\title{
Multiattribute Supply and Demand Matching Decision Model for Online-Listed Rental Housing: An Empirical Study Based on Shanghai
}

\author{
Lingyan Li $\mathbb{D},{ }^{1}$ Jiangying An, ${ }^{1}$ Yan Li $\mathbb{D}^{,},{ }^{2}$ and Xiaotong Guo ${ }^{1}$ \\ ${ }^{1}$ School of Management, Xi'an University of Architecture and Technology, Xi'an 710055, China \\ ${ }^{2}$ School of Management, Xi'an Polytechnic University, Xi'an 710048, China \\ Correspondence should be addressed to Yan Li; sayidli@xpu.edu.cn
}

Received 22 April 2020; Revised 10 June 2020; Accepted 23 June 2020; Published 1 August 2020

Guest Editor: Chi-Hua Chen

Copyright (c) 2020 Lingyan Li et al. This is an open access article distributed under the Creative Commons Attribution License, which permits unrestricted use, distribution, and reproduction in any medium, provided the original work is properly cited.

The mismatch between the supply and demand of online-listed rental housing (ORH) is an important factor restricting the operational efficiency of online rental service platforms. However, extant literature pays little attention to this problem. This study proposes an ORH multiattribute supply and demand matching decision model based on the perceived utility of matching both sides of this market. The model considers the multiattribute information of ORH, such as area, transportation, rent, room, and interior decoration, and quantifies their perceived utility values based on the theory of disappointment. Thereafter, we construct the matching decision model and verify it for feasibility by applying it to Shanghai's ORH supply and demand information-our empirical case. The results show that this method can be applied to online rental housing platforms and meet the supply and demand matching requirements to the greatest extent. The constructed model takes into account the perceptions of both supply and demand parties, may promote the effective matching of ORH supply and demand, and bears theoretical implications for the improvement of rental housing matching in ORH platforms.

\section{Introduction}

Matching supply and demand (SAD) directly affects the success of online trading. However, regarding rental housing, efficiency in matching SAD is not high [1]; many countries around the world have rental housing markets characterized by mismatches in SAD [2]. In terms of rental expenses, the US' traditional housing market, for example, offers properties with higher rental prices than residents can afford [3]. Other examples are Germany, where rented homes do not match regional SAD [4], and Nigeria, where the speed and scale of housing supply are smaller than the demand, causing inefficiency in the country's ability to meet the housing needs of low-income earners [5]. Similarly, in China, the rental housing SAD structure is incongruent $[6,7]$. This shows that traditional rental housing supply structures are incapable of matching personalized demands, and the mismatch between the quality and quantity of ORH leads to this discrepancy between the rental housing market's SAD, which seriously hinders the efficiency of rental housing service platforms. Therefore, not only can the creation of an effective matching method for online rental housing platforms solve the operational inefficiency of the rental housing market but can also promote the rapid development of the rental market.

To promote the effective matching of rental housing online, some scholars have made various attempts to study the SAD matching of ORH. So far, the matching model of $\mathrm{ORH}$ is mainly a balanced search model, whose purpose is to reduce search costs $[8,9]$. There are a few models to measure the quality of supply and demand matching based on the similarities between SAD [10]. There are also models to establish a double-sided matching theory to solve the problem of public rental housing [11]. At the same time, some scholars pointed out that SAD patterns consider various housing attributes in the house matching selection 
process $[12,13]$ and that these attributes affect ORH SAD matching [14]. For example, price floors play a central role between SAD [15], while issues around house matching and comfort, transportation, the surrounding environment, and landlord services are specific indicators of tenant concerns [16]. Location is also a factor of housing mismatch [2]. The size and location of a house are considered to be necessary conditions for appropriate house matching [14]. Therefore, housing attributes play a very important role in balancing the SAD of ORH.

Although the aforementioned models proposed by extant studies can reduce the cost of searching in the matching process-considering that housing multiattribute indicators are factors in the SAD matching process-they do not promote the effective matching of ORH or the improvement of matching satisfaction between the SAD sides. In fact, when a matching decision occurs in the actual process, most subjects are in limited rationality [17]; their expected values are limited by existing information and their own expectations $[18,19]$. Thus, the final matching pair may have a higher or lower value than the expected value, leading to below-optimal satisfaction with the matching results. In addition, perceived utility is a product of a demanders' assessment of the services, values, and functions of the required items compared to their own expectations, how they weigh the perceived benefits and costs, and the value they finally put on the required items [20]. In assessing profit and loss values, the theory of disappointment reflects the same difference between actual and expected results [21]. Loomes and Sugden also believed that "disappointment" and "excitement" are key factors in making rational choices [22]. Therefore, using disappointment theory to quantify the perceived utility of both SAD can reflect the psychological activities of both sides.

In recent years, with the acceleration of urbanization, the housing problem of China's floating population has become increasingly prominent. In 2018, the floating population reached 241 million, of which 210 million required rental housing, covering an area of 6.73 billion square meters. In addition, large and medium-sized cities in China are required to build a rental housing platform to promote the matching efficiency of rental housing. However, the housing rental market is undeveloped and has many problems, such as low supply efficiency, lack of diverse supply systems, and low capability to meeting people's housing demand $[6,23]$. Among them is Shanghai, the central city of China, with a relatively large annual flow of floating population and a great demand for rental housing. Therefore, taking Shanghai as our case study may help understand and reflect the problems of other cities. This is of great significance for promoting the development of the rental housing market.

In online rental housing transactions, the real estate network platform involved is a two-sided market that connects the SAD sides of rental housing through which various agents interact with one another, and the transactions cater to the needs of all the users (both SAD). Therefore, this study attempts to apply the two-sided matching theory to the housing rental market. To improve the satisfaction of both SAD sides, this study uses disappointment theory to construct quantitative perceived utility value matrices. First, we start by quantifying the utility of housing as perceived by both SAD sides based on the multiattribute matching characteristics of both sides. Second, we construct a multiattribute SAD matching decision model for ORH platforms. Finally, we adopt online SAD information from Shanghai, China, to ensure that the multiattribute information of rental housing has been identified and to empirically test the validity and rationality of the model, safeguarding the construction of an innovative method for ORH SAD matching.

The contributions of this study are twofold. First, the study constructs an effective SAD matching model for online rental housing platforms and enriches the application of the two-sided matching theory. Currently, research on twosided matching is mostly applied in the marriage market, labor market, schools, and hospitals, but is rarely used in the rental housing market, especially for application in online rental housing service platforms. Therefore, this study undertakes to verify the applicability and effectiveness of the two-sided matching theory in the rental housing market. This provides a reference and a theoretical method for cracking the SAD matching problem that has plagued online rental housing platforms with multisubject and multilevel supply methods. Second, the attributes of ORH are determined and measured. These can be easily extended to other cities and online platforms, providing reference to the feasibility of analyzing multiattribute decision-making matching problems. This also helps to improve the overall satisfaction and quality of SAD matching efforts by considering the expectations and real values of both SAD sides. In sum, this study is valuable for improving the efficiency of SAD matching for online platforms, as well as the sustainable development of the rental housing market.

The remainder of this article is arranged as follows: Section 2 presents a detailed literature review. Section 3 introduces the research materials and methods. The empirical results and discussion are presented in Section 4. Finally, Section 5 summarizes the conclusions and implications of this study.

\section{Literature Review}

2.1. Disappointment Theory. The disappointment theory, proposed by Bell [21] and Loomes and Sugden [22], is based on psychological reactions caused by the comparison of actual results with expectations [24]. Fundamentally, the disappointment theory suggests that when actual results are better than expected, policymakers will be ecstatic, when actual results are worse than expected, manufacturers will be disappointed, and that the greater the disparity between the outcome and the expectation, the greater the disappointment [21]. So far, there are three main contemporary disappointment models $[25,26]$. The first is the Bell-Loomes and Sugden disappointment model. This model essentially quantifies the "modified expected utility" of human satisfaction in the case of disappointment. The second is Gul's disappointment aversion (DA) model, which decomposes the participants' psychological cognition into disappointment 
and elation parts with respect to a new certainty equivalent. The third and the last model is Cillo and Delquiés disappointment without prior expectation model. This model does not assume that the decision maker sets a single reference point of comparison prior to a certain experience. Taking this theory into account and the idea that actual utility is a combination of subjective utility functions and disappointment and exhilaration functions [21], this paper uses the disappointment theory to calculate the perceived utility values of both SAD sides.

In recent years, many scholars have quantified the satisfaction of matching objects based on the disappointment theory. For example, Quan et al.'s study explored customer psychological satisfaction based on customer disappointment and pleasure behaviors, and their method promotes retailer pricing and inventory decisions [27]. Similarly, $\mathrm{Ma}$ et al. established a SAD matching model for the electricity retail industry by considering the disappointment of sensitive customers and new electricity retail companies by considering the pleasant psychological perception and obtaining the perceived utility of both parties. This method is verified to be beneficial for the management of a high-quality electricity market. Zhang et al. built a matching optimization model that maximizes satisfaction by calculating the disappointment and excitement associated with both SAD sides based on the disappointment theory [28]. Zhao et al. proposed a two-sided matching model to elaborate the preference order of SAD by considering the participants' psychological perception. Using the functions of disappointment and cheerfulness, this model effectively improves the carpool matching problem [26]. Another example is that by Fan et al., who proposed a two-way matching method that considers the psychological behavior of the agents of both parties and constructed a two-objective optimization model to obtain satisfactory matching results [29]. These models maximize the satisfaction of both SAD sides, and by considering the degree of their disappointment and elation, these models effectively reflect the perception activities of both sides, which is conducive to promoting the improvement of the satisfaction of SAD.

2.2. Two-Sided Matching. The two-sided matching theory originated from a study on marriage matching that focused on satisfying both parties with matching results according to the requirements of SAD sides [30]. Gale and Shapley, from which Shapley became the 2012 Nobel laureate in economics, first proposed the G-S algorithm for stable matching based on the strong preference information given by both men and women [31]. Later, Roth, another Nobel laureate in economics, applied the G-S algorithm to the hospital internship market [30]. Since then, the two-sided matching theory has been developed and widely used in various fields such as staff and job matching, data trading market matching, commodity trading issues, and college admission issues. At the same time, some scholars have proposed a variety of matching methods, including the deferred algorithm [32], evolutionary algorithm [33, 34], and multiattribute preference decision-making methods [35].
Nonetheless, the two-sided matching theory has proved to have a wide range of practical applications.

With the popularity of the Internet, some scholars have begun to talk about the application of the two-sided matching theory to the SAD matching problems of many online transactions. For the second-hand housing market, taking the online rental-sale matching problem as an example, Wang et al. established a two-sided matching decision method based on heterogeneous information and association, the feasibility of which was verified [36]. In the electronic market environment, Gao et al. provided a stable multilateral automated negotiation system model and showed that this model can promote effective matching between the SAD sides. For the power purchase market [37], Kong et al. proposed a SAD matching model for power retailers and buyers of cellular networks based on the two-sided matching theory, which solves the energy management problem of microgrid-connected cellular networks for the small- and medium-sized market of the sharing economy [38]. Xia et al. constructed a two-sided matching model that promotes the maximization of the interests of buyers, sellers, and agents and improves the matching efficiency thereof. For the hospital's expertoutpatient matching appointment system [39], Yang et al. constructed a matching model based on the two-sided matching theory that improves the effectiveness of medical treatment [40]. These models built by scholars based on the two-sided theory have solved the problem of matching SAD in different fields.

Similarly, in the existing literature, the two-sided matching theory has been widely applied to online trading platforms and has improved the matching efficiency between SAD. Nevertheless, its application in ORH transactions is limited. In addition, existing two-sided matching decisionmaking methods rarely consider the psychological perception of disappointment or elation when the subjective desires of both parties match and when the psychological perceptions are closely related to the satisfaction of both parties in the final matching scheme. The satisfaction of the two parties needs to effectively characterize the psychological perception of both parties. Moreover, in the process of matching ORH $\mathrm{SAD}$, both sides will consider the multiattribute information of housing [12], but there are very few studies covering the multiattribute two-sided matching model. Therefore, this paper proposes a multiattribute supply-demand matching method for online rental listings based on the perceived utility.

On online house rental platforms, tenants and landlords can be regarded as two unconnected sets. Each set will evaluate the actual value of the property according to its own psychological expectations. The main goal of a matching method in this case is to promote effective matching between SAD based on the tenants' and landlords' mental perception. Therefore, this study aims to apply the two-sided matching theory to the SAD matching problem of online rental housing services to accurately characterize the SAD perceptions of both sides and to quantify the perceived utilities of both SAD based on the disappointment theory to promote satisfaction over the matching results. 


\section{Materials and Methods}

\subsection{Framework and Schematic Diagram of the Multiattribute SAD Matching Decision Model of ORH}

3.1.1. Description and Assumption. On online rental platforms, three parties are involved: suppliers, demanders, and independent intermediaries or brokers. Suppliers on online rental platforms are usually landlords with vacant houses, the demanders are the potential tenants (those with housing needs), while independent intermediaries or brokers are service organizations that assist in matching the SAD sides based on the information provided by the suppliers and demanders. In the matching process, the brokers satisfy the requirements of the SAD parties to the greatest extent according to the information provided by them. In this study, the interactions of the suppliers and demanders can be explained with a SAD matching framework as done in the following. All variable assumptions and descriptions in the paper are shown in Table 1.

This study describes the matching characteristics of SAD sides. If the tenant is $T$, then $T=\left\{T_{1}, T_{2}, \ldots, T_{m}\right\}$, where $T_{i}$ is the $i$ tenant, and $i \in M=\{1,2, \ldots, m\}$. If a collection of landlords is $L$, then $L=\left\{L_{1}, L_{2}, \ldots, L_{n}\right\}$, where $L_{j}$ is the $j$ landlord, and $j \in N=\{1,2, \ldots, n\}$, and $m \leq n$. If a collection of online rental house listings displayed by the landlords on the online real estate platform is $H$, then $H=\left\{H_{1}\right.$, $\left.H_{2}, \ldots, H_{n}\right\}$, where $H_{j}$ is the $j$ online-listed rental house.

If a collection of housing attributes for evaluating $\mathrm{ORH}$ is $C$, then $C=\left\{C_{1}, C_{2}, \ldots, C_{k}\right\}$, where $C_{l}$ is the $l$ attribute of $\mathrm{ORH}, l \in K=\{1,2, \ldots, k\}$. The factors for evaluating $\mathrm{ORH}$ are region, rent, transportation convenience, units of houses, decoration, house supporting facilities, online ratings, and so on. These attributes are divided into hard requirements and soft requirements. Hard requirements are equitation requirements, while soft requirements are divided into benefitorientated requirements and cost-orientated requirements. The higher the attributes, the better the benefit-orientated requirements; the lower the attributes, the better the costorientated requirements. The tenants determine the expected value and weights of the specific attributes, while the landlord determines the evaluation value and attribute weights of the specific attributes such as their actual needs. Among them, $E=\left[e_{i l}\right]_{m \times k}$ is the expectation level matrix of tenant $T_{i}$ regarding the $\mathrm{ORH}$, and $e_{i l}$ is the expectation level of tenant $T_{i}$ regarding the attributes of ORH $C_{l} . R=\left[r_{j l}\right]_{n \times k}$ is the real evaluation matrix of landlord $L_{j}$ regarding the $\mathrm{ORH}$, and $r_{j l}$ is the real evaluation value of landlord $L_{j}$ regarding the attributes of $\mathrm{ORH} C_{l}$. Then, tenants give the attribute weight vector $w_{i l}=\left\{w_{1 l}, w_{2 l}, \ldots, w_{i l}\right\}$, where $w_{i l}$ represents the tenant's $T_{i}$ description of the importance of the attribute $C_{l}, \sum_{l=1}^{k} w_{i l}=1,0 \leq w_{i l} \leq 1$, where $w_{j l}$ is the landlord's $L_{j}$ description of the importance of the attribute $C_{l}, \sum_{l=1}^{k} w_{j l}=1,0 \leq w_{j l} \leq 1$. Then, according to the attribute values given by tenants and landlords, the weights of each attribute are determined by the entropy weight method.

Based on the above analysis and definition, the multiattribute SAD matching decision model for $\mathrm{ORH}$ can be described in Figure 1. The first step is the landlords submitting the real multiattribute evaluation value of the houses to the broker and the broker displaying the multiattribute information of those houses on the online rental platform. The second step is the tenants searching for the desired rental house on the online rental housing platform according to the expected value of each attribute of the rental houses. The third step involves the tenants measuring the real attribute value of the house through the left expected attribute value $C_{1}, C_{2}, C_{3}, \ldots, C_{p}$ and the landlords measuring the expected attribute value of the tenants through the right expected attribute value $C_{1}, C_{2}, C_{3}, \ldots, C_{k}$.

\subsubsection{Multiattribute Supply-Demand Matching Decision} Model Development. The schematic overview of the whole paper, as shown in Figure 2, presents processes and associated techniques used in this study for the construction of the multiattribute SAD matching decision model for $\mathrm{ORH}$ based on the perceived utility. The major steps of this process include (a) selecting and measuring housing multiattribute indicators for landlords and tenants to evaluate rental housing, respectively, (b) calculating the profit and loss matrices for each attribute of the landlords and tenants, (c) transforming the landlords' and tenants' profit and loss matrices into normalized profit and loss matrices, (d) calculating the perceived utility matrix for each attribute of the landlords and tenants, (e) determining the weight of each attribute, (f) transforming the landlords' and tenants' perceived utility matrices of each attribute into a comprehensive perceived utility matrix, (g) establishing a multiattribute SAD matching decision model for $\mathrm{ORH}$, and (h) verifying the feasibility of the model based on the actual case.

From Figure 2, the schematic overview of the multiattributes based on the perceived utility is established for supplier-demander interactions on online rental platforms. Through the web crawler method, the expected values and evaluation values of various housing attributes for both SAD were collected. This was followed by selecting seven multiattribute indicators of housing through word frequency analysis and semantic network analysis. These include district, traffic convenience, rent, living room, house supporting facilities, decoration, and online ratings. These attributes were then measured. Moreover, the profit and loss matrices of each housing attribute of the SAD were obtained based on the profit and loss function method. The method can measure the benefits and costs of both SAD. Next, we transformed the profit and loss matrices of the SAD into standardized profit and loss matrices by normalizing functions, which can unify the dimensions of each housing attribute. Furthermore, the perceived utility matrix of each housing attribute of the SAD was obtained based on the disappointment and elation function. Considering the interaction between the housing attributes, the entropy weight method was used to obtain the weight of each housing attribute, and the perceived utility matrix of both the SAD was converted into a comprehensive perceived utility matrix. In addition, based on a comprehensive perceptual utility matrix, the multiattribute SAD matching decision model for $\mathrm{ORH}$ was proposed. The model was then converted into a single-objective optimization model by a linear weighted method. Finally, to illustrate its 
TABLE 1: Variable descriptions.

\begin{tabular}{|c|c|}
\hline Nomenclature & \\
\hline$T$ & Collection of tenants \\
\hline$L$ & Collection of landlords \\
\hline$H$ & Collection of rental housing \\
\hline C & Collection of rental housing attributes \\
\hline E & The expectation level matrix of the tenant \\
\hline$e_{i l}$ & Level of expectations given by the $i$ tenant for the $l$ attribute of online rental houses \\
\hline$R$ & The real evaluation matrix of the landlord \\
\hline$r_{j l}$ & Level of real evaluation given by the $j$ landlord for the $l$ attribute of online rental houses \\
\hline$w_{i l}$ & The weight given by the $i$ tenant to the $l$ attribute of ORH \\
\hline$w_{j l}$ & The weight given by the $j$ landlord to the $l$ attribute of ORH \\
\hline$D_{l}$ & Profit and loss matrix of the tenant under the $l$ attribute \\
\hline$d_{i j l}$ & Profit and loss value of the $i$ tenant with respect to the $j$ landlord under the $l$ attribute \\
\hline$p_{i j}$ & Transaction rents \\
\hline$F_{l}$ & Profit and loss matrix of the landlord under the $l$ attribute \\
\hline$a_{i j l}$ & Profit and loss value of the $j$ landlord with the $i$ tenant under the $l$ attribute \\
\hline$D_{1}^{\prime}$ & Normative profit and loss matrix of the $i$ tenant under the $l$ attribute \\
\hline$d_{i j l}^{\prime}$ & Normative profit and loss value of the $i$ tenant with respect to the $j$ landlord under the $l$ attribute \\
\hline$F_{l}^{\prime l l}$ & Normative profit and loss matrix of the $j$ landlord under the $l$ attribute \\
\hline$a_{i j l}^{\prime}$ & Normative profit and loss value of the $j$ landlord with the $i$ tenant under the $l$ attribute \\
\hline$V_{l}^{b}$ & Tenant's perceived utility matrix under attribute $l$ \\
\hline$V_{l}^{s}$ & Landlord's perceived utility matrix under attribute $l$ \\
\hline$V$ & Tenant's comprehensive perceived utility matrix \\
\hline$V \prime$ & Landlord's comprehensive perceived utility matrix \\
\hline$x_{i j}$ & $0-1$ variable \\
\hline$Z$ & The overall satisfaction value \\
\hline
\end{tabular}

Greek symbols

$\alpha$

The delight parameter

$\beta \quad$ The disappointment avoidance parameter

Abbreviations

SAD

$\mathrm{ORH}$
Supply and demand

Online-listed rental housing

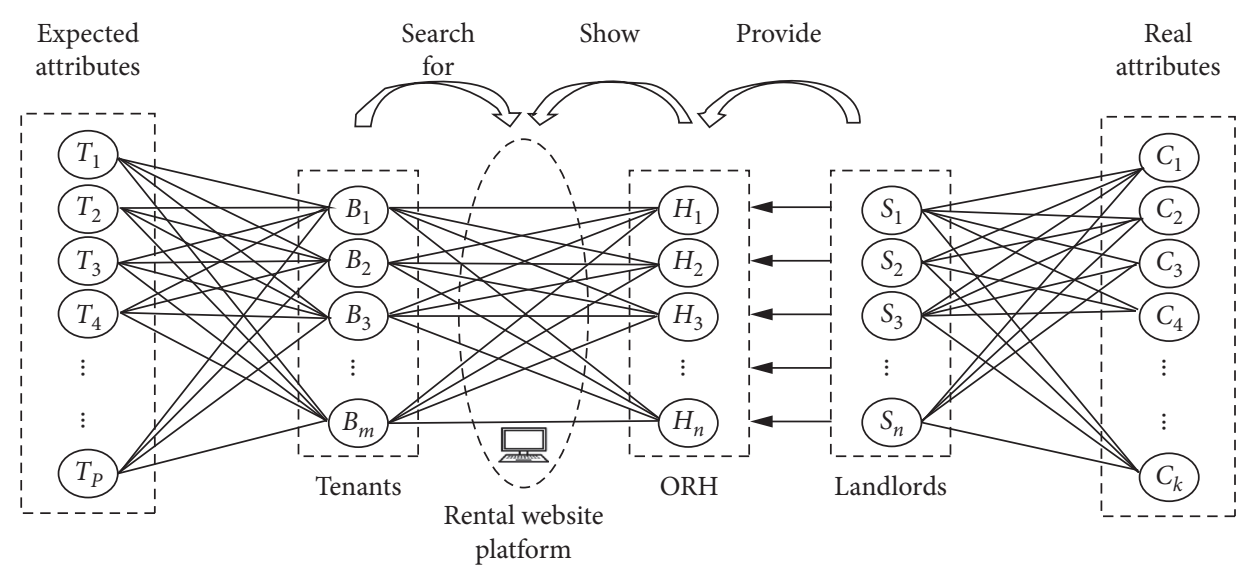

FIGURE 1: Multiattribute SAD matching decision model for the ORH matching process.

applicability and test its effectiveness, the model was applied to evidence from Shanghai.

\subsection{Multiattribute SAD Matching Decision Model for ORH Platform Transactions Based on the Perceived Utility}

3.2.1. Basis for the Construction of Profit and Loss Matrices. For both SAD sides, benefits and losses occur during the process of matching the SAD of ORH. These benefits and losses are subject to psychological perception, and psychological perception is closely related to the satisfaction of both SAD sides in the final matching scheme. This study specifically describes the values of the profits and losses of both suppliers and the demanders as follows.

When the expectation value of tenant $T_{i}$ for an attribute of the rental house $C_{l}$ is inferior to the real evaluation value of landlord $L_{j}$ in terms of this attribute, profits occur; 


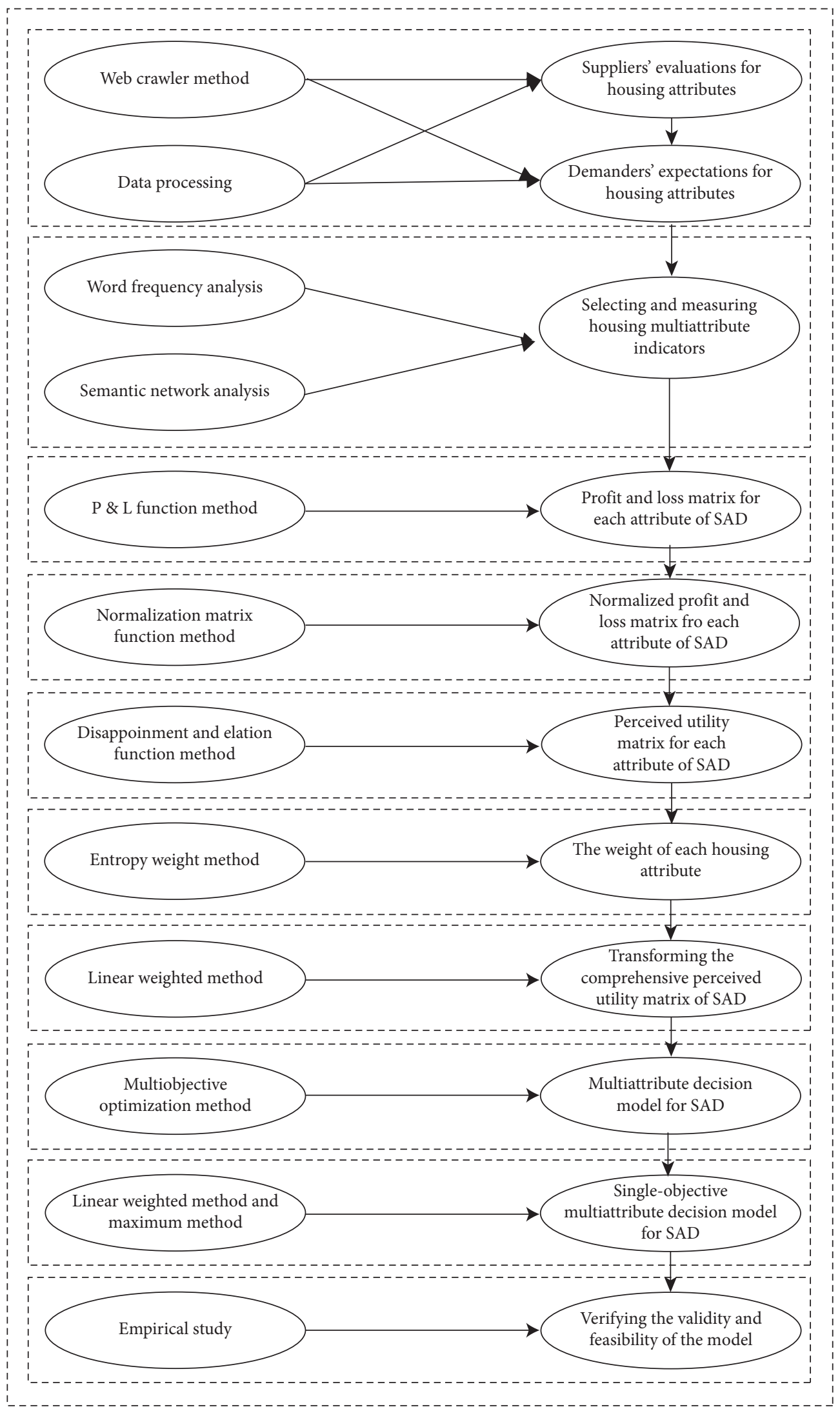

FIGURE 2: Schematic overview of the multiattribute SAD matching decision model for ORH based on the perceived utility. 
otherwise, losses occur. The above benefits and losses are quantified as follows.

If $D_{l}=\left[d_{i j l}\right]_{m \times n}$ is the profit and loss matrix of tenant $T_{i}$ under attribute $C_{l}$, then $d_{i j l}$ is the profit or loss of landlord $L_{j}$ under attribute $C_{l}$. Considering that tenant $T_{i}$ will put forward different requirements according to their own expectations, $d_{i j l}$ is calculated as follows.

When attribute $C_{l}$ is rent, in order to ensure the fairness of online transactions, the transaction rent is set to the middle value of the tenants'. expected rent and the landlords' $L_{j}$ expected rent, and the calculation equation of the transaction rents $p_{i j}$ and $d_{i j l}$ are as follows:

$$
p_{i j}=\frac{r_{j l}+e_{i l}}{2}, \quad i \in M, j \in N, l \in K \text {. }
$$

When attribute $C_{l}$ is rent, $d_{i j l}$ is calculated by the following three cases [41]:

Case 1: when $e_{i l}=r_{j l}$, the tenant's $T_{i}$ performance to landlord $L_{j}$ is neither a gain nor a loss.

Case 2: when $e_{i l}<p_{i j}<r_{j l}$, the tenant's $T_{i}$ performance to landlord $L_{j}$ is a loss. The loss would be $1-\left(p_{i j} / e_{i l}\right)$.

Case 3: when $e_{i l}>r_{j l}$, the tenant's $T_{i}$ performance to landlord $L_{j}$ is gain. The gain is 1 .

Therefore, the equation for calculating $d_{i j l}$ is as follows:

$$
d_{i j l}= \begin{cases}0, & e_{i l}=r_{j l}, \\ 1-\frac{p_{i j}}{e_{i l}}, & e_{i l}<p_{i j}<r_{j l}, \\ 1, & e_{i l}>p_{i j}>r_{j l}, \\ i \in M, j \in N, l \in K .\end{cases}
$$

When attribute $C_{l}$ is not rent, there are three forms of requirements, Wang et al. gave everyone's gains and losses based on expectations, and the equation is as follows [42]:

(1) When tenant $T_{i}$ has a hard requirement of attribute $C_{l}$, hard constraints refer to covenants that must be satisfied by bundle conditions. When the value of $e_{i l}$ is equal to the value of $r_{j l}$, tenant $i$ and landlord $J$ can be matched. When the value of $e_{i l}$ is not equal to the value of $r_{j l}$, tenant $T_{i}$ and landlord $L_{j}$ cannot be matched. Then, the equation for calculating $d_{i j l}$ is as follows:

$$
d_{i j l}= \begin{cases}1, & r_{j l}=e_{i l}, \\ 0, & r_{j l} \neq e_{i l}, \\ & i \in M, j \in N, l \in K .\end{cases}
$$

(2) When tenant $T_{i}$ has a benefit requirement of attribute $C_{l}$, the larger the attribute value of the benefittype attribute, the better. $d_{i j l}$ is calculated by the following three cases:

Case 1: when $e_{i l}=r_{j l}$, the tenant's $T_{i}$ performance to landlord $L_{j}$ is neither a gain nor a loss under attribute $C_{l}$.
Case 2: when $e_{i l}<r_{j l}$, the tenant's $T_{i}$ performance to landlord $L_{j}$ is a gain under attribute $C_{l}$. The gain is $r_{j l}-e_{i l}$.

Case 3: when $e_{i l}>r_{j l}$, the tenant's $T_{i}$ performance to landlord $L_{j}$ is a loss under attribute $C_{l}$. The loss is $r_{j l}-e_{i l}$.

Therefore, when attribute $C_{l}$ is a benefit requirement, the equation for calculating $d_{i j l}$ is as follows:

$$
d_{i j l}= \begin{cases}0, & r_{j l}=e_{i l}, \\ r_{j l}-e_{i l}, & r_{j l} \neq e_{i l}, \\ & i \in M, j \in N, l \in K .\end{cases}
$$

(3) When tenant $T_{i}$ has a cost-type requirement of attribute $C_{l}$, the lower the value of the cost attribute, the better. $d_{i j l}$ is calculated by the following three cases:

Case 1: when $e_{i l}=r_{j l}$, the tenant's $T_{i}$ performance to landlord $L_{j}$ is neither a gain nor a loss given attribute $C_{l}$.

Case 2: when $e_{i l}<r_{j l}$, the tenant's $T_{i}$ performance to landlord $L_{j}$ is a loss given attribute $C_{l}$. The loss is $e_{i l}-r_{j l}$.

Case 3: when $e_{i l}>r_{j l}$, the tenant's $T_{i}$ performance to landlord $L_{j}$ is a gain given $C_{l}$. The gain is $e_{i l}-r_{j l}$.

Therefore, when attribute $C_{l}$ is a cost-type requirement, the equation for calculating $d_{i j l}$ is as follows:

$$
d_{i j l}= \begin{cases}0, & r_{j l}=e_{i l}, \\ e_{i l}-r_{j l}, & r_{j l} \neq e_{i l}, \\ & i \in M, j \in N, l \in K .\end{cases}
$$

Similarly, landlord $L_{j}$ should consider whether the tenant's $T_{i}$ expected rent is within an acceptable range and meets the requirements for the ORH's area. If $F_{l}=\left[a_{i j l}\right]_{m \times n}$ is the profit and loss matrix of landlord $L_{j}$ for attribute $C_{l}$ and $a_{i j l}$ is the profit and loss value of landlord $L_{j}$ with respect to tenant $T_{i}$ for attribute $C_{l}$, then the calculation equation of $a_{i j l}$ is as follows:

$$
\begin{aligned}
& a_{i j l}= \begin{cases}0, & r_{j l}=e_{i l}, \\
\frac{p_{i j}}{r_{j l}}-1, & e_{i l}<p_{i j}<r_{j l}, \\
1, & r_{j l}<p_{i j}<e_{i l}, \\
& i \in M, j \in N, l \in K,\end{cases} \\
& a_{i j l}= \begin{cases}1, & e_{i l}=r_{i l}, \\
0, & e_{i l} \neq r_{j l},\end{cases} \\
& i \in M, j \in N, l \in K .
\end{aligned}
$$

The SAD sides concern about some attributes of online rental house. As the dimensions of these attributes are different, $D_{l}=\left[d_{i j l}\right]_{m \times n}$ and $F_{l}=\left[a_{i j l}\right]_{m \times n}$ of the profit and 
loss matrices of both parties in the transaction were converted into normative $D_{l}^{\prime}=\left[d_{i j l}^{\prime}\right]_{m \times n}$ and $F_{l}^{\prime}=\left[a_{i j l}^{\prime}\right]_{m \times n}$, among which the calculation equations of $d_{i j l}{ }^{\prime}$ and $a_{i j l}{ }^{\prime}$ are as follows [43]:

$$
\begin{aligned}
& d_{i j l}^{\prime}=\frac{d_{i j l}}{\max \left|d_{i j l}\right|}, \quad i \in M, j \in N, l \in K, \\
& a_{i j l}^{\prime}=\frac{a_{i j l}}{\max \left|a_{i j l}\right|}, \quad i \in M, j \in N, l \in K .
\end{aligned}
$$

3.2.2. Basis of the Construction of Perceptual Utility Matrices. Based on the disappointment theory, the normalized profit and loss matrices $D_{l}^{\prime}=\left[d_{i j l}^{\prime}\right]_{m \times n}$ and $F_{l}^{\prime}=\left[a_{i j l}^{\prime}\right]_{m \times n}$ are transformed into the perceived utility matrices $V_{l}^{b}=\left[v_{i j l}^{b}\right]_{m \times n}$ and $V_{l}^{s}=\left[v_{i j l}^{s}\right]_{m \times n}$, and the perceived utility value of both supplier and the demander is determined by the disappointment and delight function $\varphi(x)$ of Grant and Kajii [44], which can be expressed as [26]

$$
\varphi(x)= \begin{cases}1-\alpha^{x}, & x \geq 0, \\ \beta^{(-x)}-1, & x<0 .\end{cases}
$$

$\alpha$ is the delight parameter satisfying $0<\alpha<1$, while $\beta$ is the disappointment avoidance parameter satisfying $0<\beta<1$. The larger $\alpha$ and $\beta$ are, the lower the subject's perceived value of the matching results is compared to the expected value. In order to facilitate calculation, Laciana and Weber measured the beta value in accordance with most subject behavioral preferences [45], $0.7 \leq \alpha \leq 0.9,0.7 \leq \beta \leq 0.9$, In this paper, $\alpha$ and $\beta$ take the same value. Therefore, if $\alpha=\beta=0.8$, then, $V_{l}^{b}=\left[v_{i j l}^{b}\right]_{m \times n}$ and $V_{l}^{s}=\left[v_{i j l}^{s}\right]_{m \times n}$, and the calculation equations are as follows [26]:

$$
\begin{array}{ll}
v_{i j l}^{b}=\varphi\left(d_{i j l}^{\prime}\right), \quad i \in M, j \in N, l \in K, \\
v_{i j l}^{s}=\varphi\left(a_{i j l}^{\prime}\right), \quad i \in M, j \in N, l \in K .
\end{array}
$$

The tenant's $T_{i}$ comprehensive perceptual utility matrix $V=\left[v_{i j}^{b}\right]_{m \times n}$ is constructed according to the tenant's $T_{i}$ perceptual utility matrix $V_{l}^{b}=\left[v_{i j l}^{b}\right]_{m \times n}$, where the calculation equation of $v_{i j}^{b}$ is as follows [46]:

$$
v_{i j}^{b}=\sum_{l=1}^{k} w_{i l} v_{i j l}^{b}, \quad i \in M, j \in N, l \in K .
$$

Similarly, a comprehensive perceived utility matrix $V_{I}=$ $\left[v_{i j}^{s}\right]_{m \times n}$ of landlord $L_{j}$ is constructed, where the calculation equation of $v_{i j}^{s}$ is as follows [46]:

$$
v_{i j}^{s}=\sum_{l=1}^{k} w_{j l} v_{i j l}^{s}, \quad i \in M, j \in N, l \in K .
$$

In the constructed comprehensive perceived utility matrix, the larger $v_{i j}^{b}$ and $v_{i j}^{s}$, the higher the satisfaction of both suppliers and demanders.
3.2.3. Construction of Supply-Demand Matching Model Based on the Perceived Utility. Set $x_{i j}$ represents a 0-1 variable, where $x_{i j}=0$ represents that tenant $T_{i}$ and landlord $L_{j}$ do not match, while $x_{i j}=1$ represents that tenant $T_{i}$ and landlord $L_{j}$ match. According to the comprehensive perceived utility matrices $V$ and $V^{\prime}$, under the requirement of stable matching, the following two-objective optimization model can be established to maximize the comprehensive perceived utility of suppliers and demanders:

$$
\begin{array}{ll}
\max & Z_{1}=\sum_{i=1}^{m} \sum_{j=1}^{n} v_{i j}^{b} x_{i j}, \quad i \in M, j \in N, \\
\max & Z_{2}=\sum_{i=1}^{m} \sum_{j=1}^{n} v_{i j}^{s} x_{i j}, \quad i \in M, j \in N, \\
\text { s.t. } & \sum_{i=1}^{m} x_{i j} \leq 1, \quad j \in N, \\
& \sum_{j=1}^{n} x_{i j}=1, \quad i \in M, \\
& \sum_{j=1}^{n} x_{i j} r_{i j}=1, \quad i \in M, \\
& x_{i j}=0 \text { or } 1, \quad i \in M, j \in N .
\end{array}
$$

Equations (15a) and (15b) are the objective functions, respectively, maximizing the sums of the perceived utilities of suppliers and demanders in the final matching result. Equations (15c) and (15d) are the requirements of twosided matching. Equation (15c) is an inequality requirement because $m \leq n$, which means that each tenant $T_{i}$ can match at most one landlord $L_{j}$. Equation (15d) is an equality constraint, meaning that each landlord $L_{j}$ can only match one tenant $T_{i}$, while equation (15e) is a hard requirement.

In order to realize the multiobjective optimization model and maximize the overall matching degree between suppliers and demanders, the linear weighting method can be used to weigh equations (15a) and (15b). $w_{1}$ and $w_{2}$ are the weights of $Z_{1}$ and $Z_{2}$, respectively, to satisfy $0 \leq w_{1}, w_{2} \leq 1$, and $w_{1}+w_{2}=1$. Considering the fairness of the suppliers and demanders, this paper provides that $w_{1}=w_{2}=0.5$, and the two-objective model (15a)-(15f) can be transformed into a single-objective optimization model (16a)-(16e)

$$
\begin{gathered}
\max \quad Z=0.5 Z_{1}+0.5 Z_{2}, \\
\text { s.t. } \quad \sum_{i=1}^{m} x_{i j} \leq 1, \quad j \in N, \\
\sum_{j=1}^{n} x_{i j}=1, \quad i \in M,
\end{gathered}
$$




$$
\begin{gathered}
\sum_{j=1}^{n} x_{i j} r_{i j}=1, \quad i \in M, \\
x_{i j}=0 \text { or } 1, \quad i \in N, j \in M .
\end{gathered}
$$

This single-objective optimization model will attempt to apply the improved genetic algorithm given the large scale of this study's two-sided matching and requirements $[47,48]$.

3.2.4. Solution Procedure. According to the above analysis, the proposed method's solution procedure for the multiattribute ORH SAD matching decision model is summarized as follows:

Step 1: collection, selection, and measurement of Shanghai's housing property SAD information from its online rental platforms using a web crawler

Step 2: calculation of the profit and loss matrices of SAD based on equations (1)-(7)

Step 3: calculation of the normative profit and loss matrices of SAD based on equations (8) and (9)

Step 4: calculation of the perceived utility matrix of SAD based on equations (11) and (12)

Step 5: calculation of the comprehensive perceived utility matrix of SAD based on equations (13) and (14) followed by the conversion of the multiobjective optimization model to a single-objective optimization model based on the comprehensive perceived utility matrix in equations (15a)-(15f) and (16a)-(16e)

Step 6: solving the optimization model in equations (16a)-(16e) to obtain the optimal matching pairs of online rental platforms' SAD sides using a genetic algorithm

3.3. Data and Measurements. This section includes three sections. First, we introduce the background of the Shanghai rental housing market and explain why it is suitable for testing our study. Second, we introduce the data set, which is from Shanghai's current online rental platforms. Third, we introduce the selection and measurement of multiattribute indicators.

\subsubsection{Background of Shanghai's Rental Housing Market.} Shanghai is one of China's four municipalities. It is located in the east of China at the mouth of the Yangtze River and is the leading city in the Yangtze River Economic Belt. In 2017, Shanghai was organized by 16 districts and counties as shown in Figure 3, including Huangpu, Xuhui, Changning, Jingan, Hongkou, Yangpu, Minhang, Baoshang, Jiading, and Pudong. By the end of 2018, the total population of Shanghai had reached 24.24 million, of which 9.76 million was the floating population, ranking the highest in the country.

Since 1980, China's housing market has been dominated by sales, while the rental market developed slowly. However, with the acceleration of China's urbanization process-a powerful means of regulating urban real estate, retaining the working population, and attracting new talents-the rental housing market has become an important part of deepening the reform of the housing system and an important way to achieve the goal of improving urban residents' quality of life. Shanghai, as China's largest economic center city, attracts a large floating population. Since 2011, Shanghai's permanent migrant population has remained above 9.6 million per year, which accounts for more than $40 \%$ of the total resident population, as shown in Figure 4. This huge population size has resulted in an increase in living demands. Therefore, the development of Shanghai's rental housing market requires urgent attention.

In July 2017, China's Ministry of Housing and Construction and nine other departments jointly issued the "Notice on Accelerating the Development of Housing Rental Market in Large- and Medium-sized Cities with Net Population Inflow," requiring large- and medium-sized cities with a net inflow of population to set up government-backed rental housing service platforms. Therefore, Shanghai now has a public house leasing service platform. In addition to this, Shanghai has many private online leasing platforms, including Lianjia.com, Anjuke, and Fangtianxia. Many people use these platforms to find listings. Online platforms can display a variety of information about the listed property, such as the number of rooms, the size of the property, the degree of decoration, and the housing facilities. The platforms also include some rent-seeking information, which helps match the SAD sides. Therefore, Shanghai is a suitable sample for testing the model constructed in this study.

3.3.2. Data Collection. Using the Python web crawler technology, on May 13th, 2019, we performed a crawling exercise on 21,762 articles from the current mainstream online rental platforms like Shanghai's housing leasing public service platform, Anjuke, Lianjia, and Fang.com. At the same time, we collected 1,739 and 929 rent-seeking messages from 58.com and Weibo, respectively, and obtained 1,226 effective massages after manually deleting unrelated data. The keywords used for detecting unrelated data included "I am an owner," "I am an intermediary," "commercial," "shop," "rent out," "office," and "office buildings." The origins of the final data are spread across 15 of Shanghai's 16 districts. The workflow used to crawl rentseeking information on 58.com is shown in Figure 5 . According to the crawled rent-seeking information shown in Table 2, there is a high degree of similarity between the housing attribute indicators considered by the potential tenants. The frequencies of the feature words related to housing area, decoration, rental price, appliances, transportation, and so on, are relatively high. Given that Shanghai's floating population has a relatively high demand for rental housing and that the consideration factors are relatively complete in the transaction, it appears that the collected rent-seeking information is adequately representative, with a strong reference for other cities as well.

3.3.3. Selection and Measurements of Multiattribute Indicators. Word frequency can reflect the importance of a word in different contexts or expressions. The higher the 


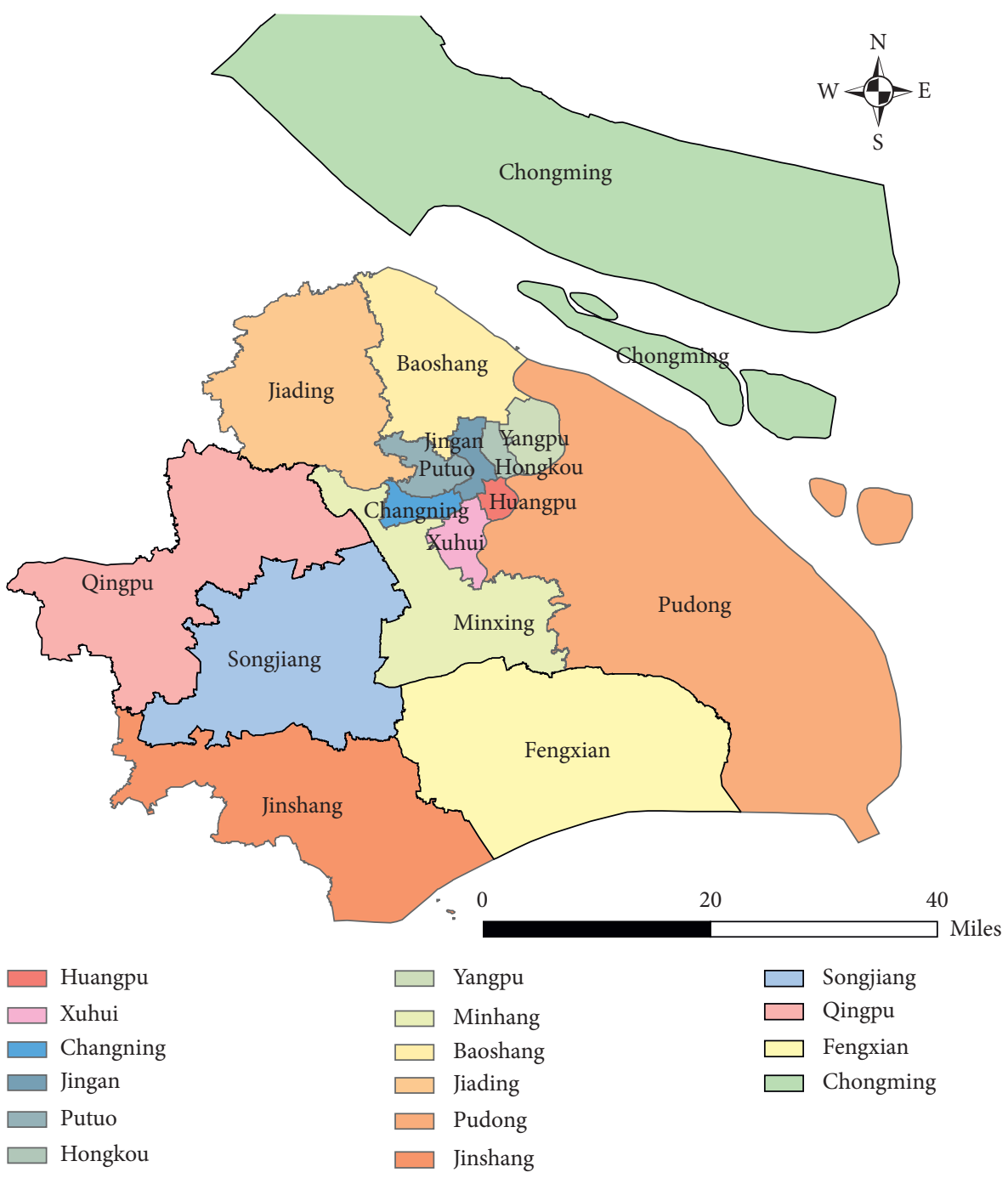

FIgure 3: Administrative divisions of Shanghai in 2017.

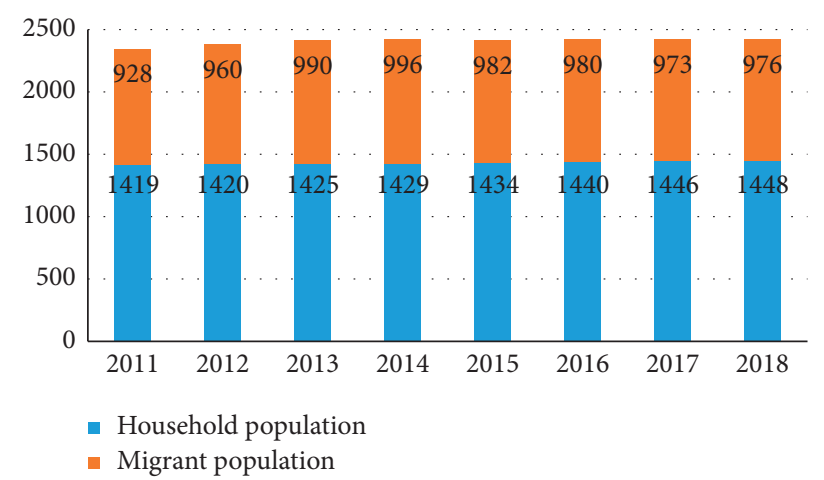

FIgURE 4: Population structure of Shanghai's permanent residents, 2011-2018 (unit: 10,000).

word frequency, the more important it is. With the aforementioned Python crawled rent-seeking messages from the "Personalized needs" page of 58.com and the comments from Weibo's "Shanghai Rent-seeking" page, this paper employs a word cloud to display the top 50 words related to property characteristics (shown in Figure 6). The top three words are "near," "rent," and "decoration" followed by "subway," "furniture," "home appliances," and "single room." The search term "Near" reflects the requirements of the housing location, while "Subway" indicates a requirement for proximity to public transportation. The characteristic value of "rent" reflects the demand for renting a house. "Room" 


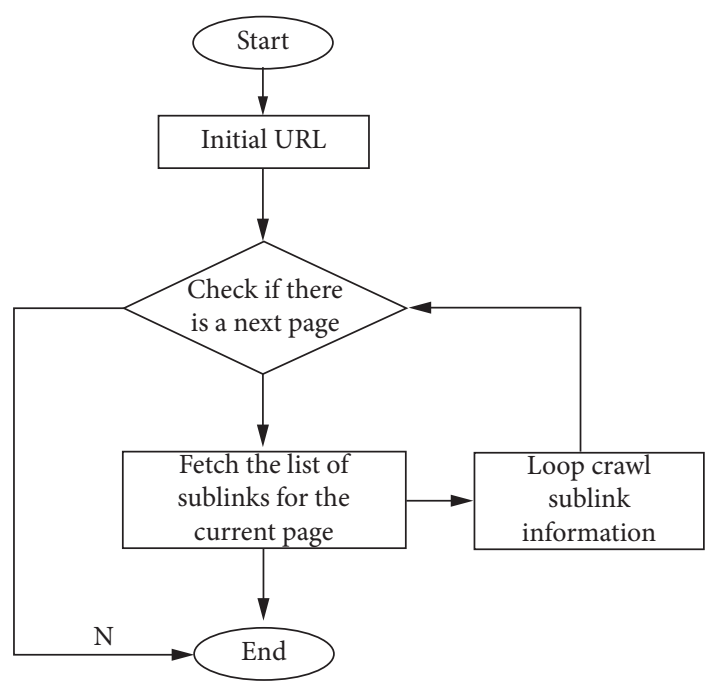

Figure 5: Workflow for crawling rent-seeking information on 58. com.

TABle 2: Tenant's rent-seeking information: frequency of feature words (top 30).

\begin{tabular}{lc}
\hline Feature words & Frequency \\
\hline Near & 186 \\
House & 137 \\
Decoration & 124 \\
Clean & 113 \\
Furniture & 109 \\
Subway & 106 \\
Rent & 94 \\
One room & 94 \\
Home appliances & 93 \\
Traffic & 80 \\
Hardcover & 80 \\
Personal & 78 \\
Subway station & 67 \\
Price & 63 \\
Cooking & 63 \\
Tidy & 60 \\
Within & 60 \\
Share & 57 \\
Two rooms & 57 \\
Paperback & 56 \\
Landlord & 56 \\
Elevator & 53 \\
Consider & 52 \\
Budget & 52 \\
Distance & 52 \\
Facility & 52 \\
Traffic & 48 \\
Complete & 45 \\
Health & 41 \\
\hline & 41 \\
\hline
\end{tabular}

indicates a requirement for a living room; "Decoration," "Furniture," and "appliances" are requirements for the aesthetics, furniture, and amenities of the house.

Although a word frequency analysis can reflect the personalized needs of the tenant by extracting high-frequency words, it cannot reflect the connections between those words. However, a semantic network analysis can visually display the relationship between elements by constructing a semantic relationship network map [49]. Therefore, for this study, we performed a text analysis of the crawled information using ROSTCM6 software. First, the crawled rent-seeking information was processed through word segmentation. Second, the high-frequency words were extracted, and the meaningless words were filtered, then the line feature words were extracted to generate VNA files, and we then imported them into NetDraw software to construct a co-occurrence matrix. Finally, the semantic relationship network map (shown in Figure 7) of the rent-seeking information was generated. As seen in Figure 7, "near," "rent," "decoration," "appliances," and "subway" are the central nodes of the entire network, reflecting the similarity of different tenants in selecting online rental houses. Comprehensively, tenants conduct a systematic investigation of overall quality when searching rental houses. On the one hand, in terms of location and proximity to transportation, tenants share similar requirements, reflected by the "subway," "traffic," and "near" nodes. On the other hand, in terms of the overall quality of the houses, tenants require properties with facilities, as reflected by the "appliances," "furniture," and "kitchen" nodes. In fact, these characteristic words reflect the real needs of tenants when choosing a rental house online. However, both SAD sides of ORH include institutions and/or individuals; thus, the transaction takes place between unfamiliar entities. In such a case, the authenticity of housing and the construction of the social credit system are significant for the smooth operation of platforms [50]. Therefore, this study analyzed the word cloud maps and semantic network maps and finally selected seven attributes: district, traffic convenience, rent, living room, house supporting facilities, decoration, and online ratings. These seven indicators of the crawled listing and rent-seeking information were then quantified separately, as shown in Table 3.

The entropy weight method is effective for calculating the weight and objective orderings of multiattribute indicators by applying information entropy [51]. The smaller the information entropy of the indicator, the larger the amount of information provided. Similarly, the greater the entropy's role in the comprehensive evaluation, the higher the weight. Thus, the paper uses the entropy weight method to calculate weight. For the tenants, it is necessary to pay attention to the seven attributes of area, transportation convenience, rent, living room, housing matching, decoration, and online ratings. Regarding their types, location is a hard requirement, living room, house matching, and decoration are benefit requirements, while rent and transportation convenience are cost requirements. Their weight values are $w_{1}=$ $0.302, w_{2}=0.137, w_{3}=0.193, w_{4}=0.074$,

$w_{5}=0.162, w_{6}=0.038$, and $w_{7}=0.094$. For the landlords, the main focus is location and rent. In this paper, the weight values of both attributes are 0.5 for fairness.

\section{Results and Discussion}

4.1. Results. For the construction of the model, first, we randomly selected 50 of the 1,226 tenants whose information 


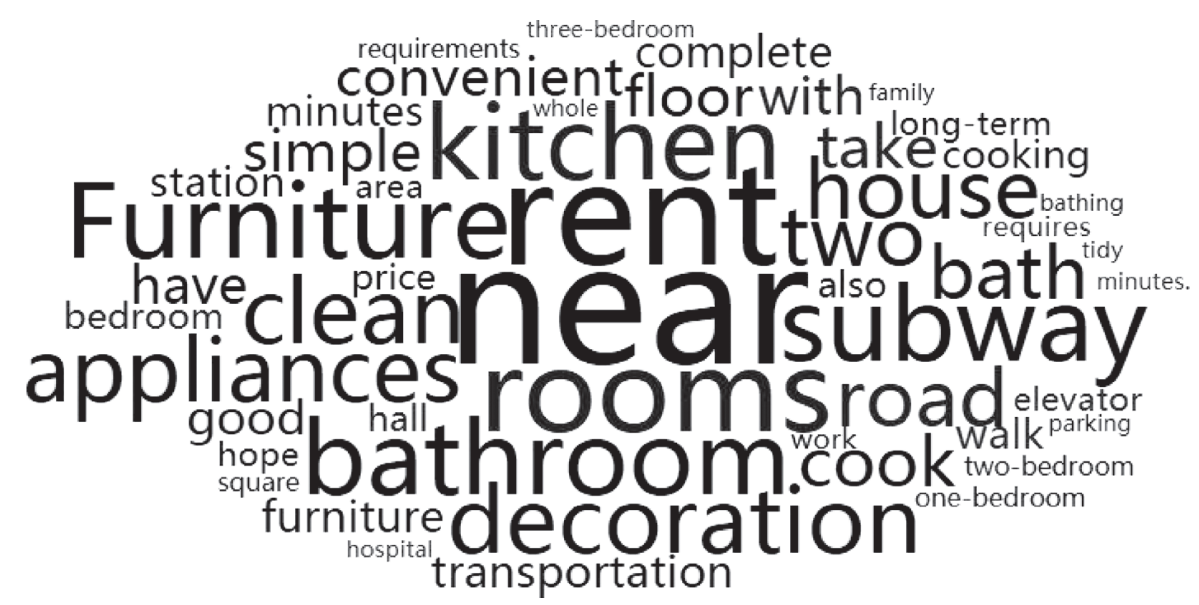

FIGURE 6: Word cloud diagram of rent-seeking information results.

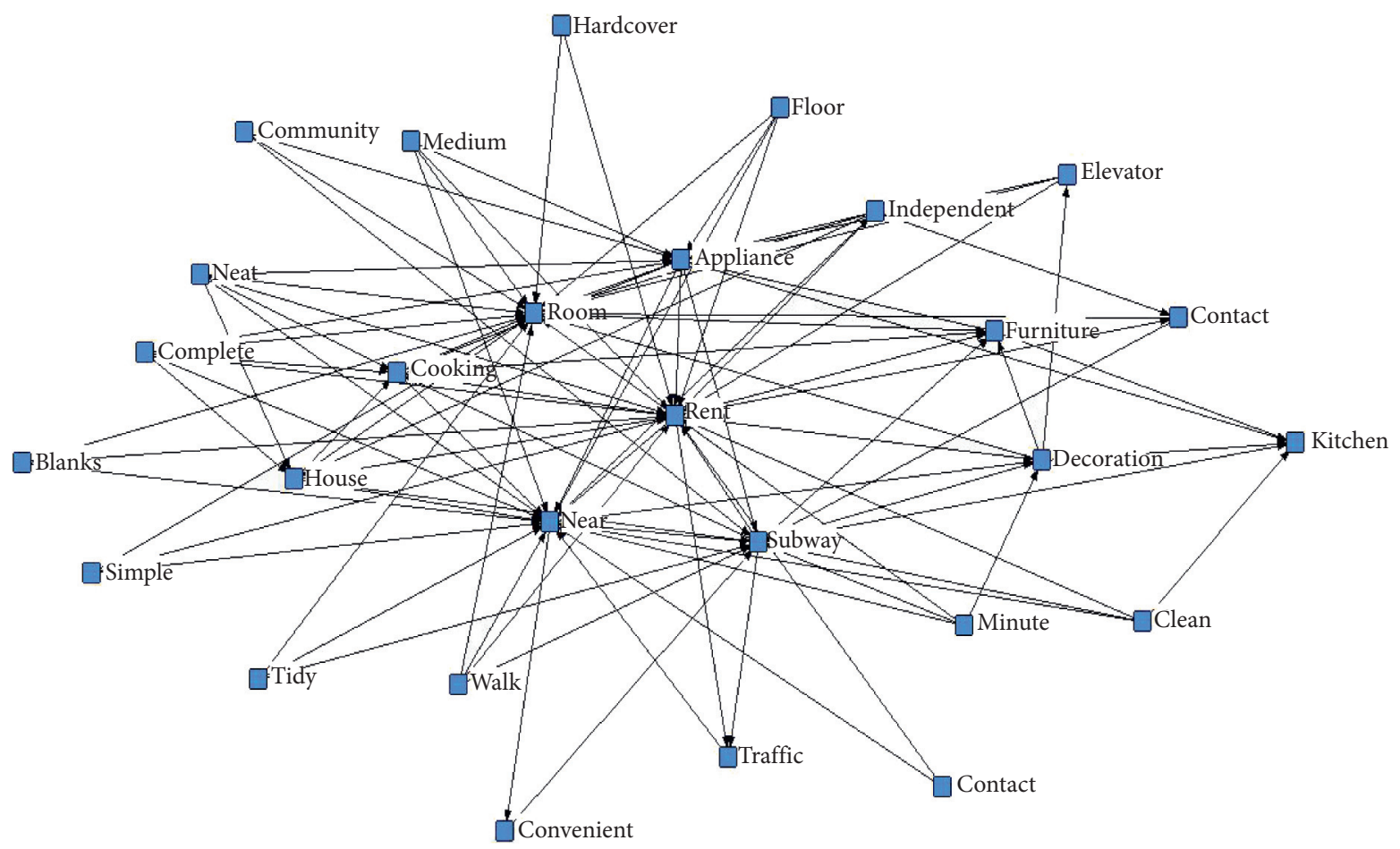

FIGURE 7: Semantic relationship network map of rent-seeking information.

was crawled; then, according to their needs, 50 landlords were selected. Second, each attribute index was measured. The landlord's evaluation values of the housing attributes are shown in Table 4, while the tenants' expectation values of housing attributes are shown in Table 5. Third, the profit and loss matrices, the standardized profit and loss matrices, the perceived utility matrices, and the comprehensive perceived utility matrices of the SAD were calculated using Matlab 2016 software. The specific steps of the calculations are as follows:

Step 1: according to Table 3, the landlords' evaluation values of the housing attributes and the tenants' expectation values of the housing attributes were measured (as shown in Tables 4 and 5, respectively).
Step 2: by using equations (1)-(7), the landlords' profit and loss matrices $F_{l}=\left[a_{i j l}\right]_{50 \times 50}$ and the tenants' profit and loss matrices $D_{l}=\left[d_{i j l}\right]_{50 \times 50}$ for location and transportation convenience were calculated (as shown in Tables 6 and 7 and Tables 8 and 9, respectively). The remaining tenants' profit and loss matrices are shown in Appendix.

Step 3: based on the landlords' and tenants' profit and loss matrices and by using equations (8) and (9), the landlords' normative profit and loss matrices $F_{l}^{\prime}=\left[a_{i j l}^{\prime}\right]_{50 \times 50}$ were calculated (as shown in Tables 10 and 11), and the tenants' profit and loss matrices $D_{l}^{\prime}=$ $\left[d_{i j l}^{\prime}\right]_{50 \times 50}$ for location and transportation convenience were also calculated (as shown in Tables 12 and 13). The 
TABLE 3: Measurement of multiattribute indicators.

\begin{tabular}{|c|c|c|c|}
\hline Variable name & Original value of the variable & Variable type & $\begin{array}{c}\text { Quantitative value of } \\
\text { the variable }\end{array}$ \\
\hline Location $\left(C_{1}\right)$ & $\begin{array}{l}\text { Huangpu, Jingan, Xuhui, Pudong, Changning, Hongkou, Yangpu, } \\
\text { Putuo, Minhang, Baoshang, Jiading, Qingpu, Fengxian, Jinshan, } \\
\text { Songjiang }\end{array}$ & $\begin{array}{l}\text { Character } \\
\text { classification }\end{array}$ & $\begin{array}{l}\text { Assign } 1 \text { to } 15 \\
\text { respectively }\end{array}$ \\
\hline $\begin{array}{l}\text { Transportation } \\
\text { convenience }\left(C_{2}\right)\end{array}$ & $\begin{array}{l}\text { It is (1) within } 500 \text { meters from the subway, (2) between } 500 \text { and } \\
1000 \text { meters away, (3) 1000-1500 meters away, (4) } 500-2000 \text { meters } \\
\text { away, and (5) } 2000 \text { meters and above away. }\end{array}$ & $\begin{array}{l}\text { Character } \\
\text { classification }\end{array}$ & $\begin{array}{l}\text { Assign } 1 \text { to } 5 \text {, } \\
\text { respectively }\end{array}$ \\
\hline Rent $\left(C_{3}\right)$ & Rent value & $\begin{array}{c}\text { Numerical } \\
\text { quantification }\end{array}$ & - \\
\hline Living room $\left(C_{4}\right)$ & One room to four or more rooms & $\begin{array}{l}\text { Character } \\
\text { classification }\end{array}$ & $\begin{array}{l}\text { Assign } 1 \text { to } 5 \text {, } \\
\text { respectively }\end{array}$ \\
\hline Appliances $\left(C_{5}\right)$ & $\begin{array}{l}\text { No, simple furniture, home appliances, basic configuration, } \\
\text { complete equipment, full-fit }\end{array}$ & $\begin{array}{l}\text { Character } \\
\text { classification }\end{array}$ & $\begin{array}{l}\text { Assign } 1 \text { to } 5, \\
\text { respectively }\end{array}$ \\
\hline Decoration degree $\left(C_{6}\right)$ & $\begin{array}{l}\text { Blank, simple decoration, medium decoration, fine decoration, } \\
\text { luxury decoration }\end{array}$ & $\begin{array}{l}\text { Character } \\
\text { classification }\end{array}$ & $\begin{array}{l}\text { Assign } 1 \text { to } 5 \text {, } \\
\text { respectively }\end{array}$ \\
\hline Online ratings $\left(C_{7}\right)$ & Low, average, good, excellent, excellent & $\begin{array}{l}\text { Character } \\
\text { classification }\end{array}$ & $\begin{array}{l}\text { Assign } 1 \text { to } 5 \text {, } \\
\text { respectively }\end{array}$ \\
\hline
\end{tabular}

TABLE 4: Landlords' evaluation values of housing attributes.

\begin{tabular}{cccccccc}
\hline$L_{n}$ & $C_{1}$ & $C_{2}$ & $C_{3}$ & $C_{4}$ & $C_{5}$ & $C_{6}$ & $C_{7}$ \\
\hline$L_{1}$ & 1 & 2 & 4300 & 1 & 4 & 4 & 4 \\
$L_{2}$ & 1 & 2 & 4000 & 1 & 4 & 3 & 5 \\
$L_{3}$ & 2 & 2 & 3200 & 1 & 4 & 4 & 4 \\
$L_{4}$ & 2 & 2 & 3000 & 1 & 3 & 3 & 3 \\
$\vdots$ & $\vdots$ & $\vdots$ & $\vdots$ & $\vdots$ & $\vdots$ & $\vdots$ & $\vdots$ \\
$L_{47}$ & 10 & 1 & 6500 & 3 & 4 & 4 & 4 \\
$L_{48}$ & 11 & 2 & 5800 & 3 & 4 & 4 & 3 \\
$L_{49}$ & 14 & 4 & 3200 & 3 & 4 & 4 & 3 \\
$L_{50}$ & 15 & 4 & 6500 & 3 & 4 & 4 & 4 \\
\hline
\end{tabular}

TABLe 5: Tenants' expectation values of housing attributes.

\begin{tabular}{cccccccc}
\hline$T_{m}$ & $C_{1}$ & $C_{2}$ & $C_{3}$ & $C_{4}$ & $C_{5}$ & $C_{6}$ & $C_{7}$ \\
\hline$T_{1}$ & 1 & 1 & 4000 & 1 & 4 & 4 & 4 \\
$T_{2}$ & 1 & 2 & 3800 & 1 & 3 & 3 & 3 \\
$T_{3}$ & 1 & 2 & 6500 & 2 & 4 & 3 & 2 \\
$T_{4}$ & 2 & 2 & 3000 & 1 & 3 & 4 & 3 \\
$\vdots$ & $\vdots$ & $\vdots$ & $\vdots$ & $\vdots$ & $\vdots$ & $\vdots$ & $\vdots$ \\
$T_{47}$ & 14 & 5 & 1500 & 2 & 2 & 2 & 2 \\
$T_{48}$ & 15 & 3 & 2200 & 1 & 4 & 3 & 2 \\
$T_{49}$ & 15 & 3 & 3500 & 2 & 4 & 2 & 3 \\
$T_{50}$ & 15 & 3 & 6500 & 3 & 4 & 3 & 5 \\
\hline
\end{tabular}

TABle 6: Profit and loss matrix $F_{1}=\left[a_{i j 1}\right]_{50 \times 50}$ for landlords' housing location.

\begin{tabular}{cccccccc}
\hline$a_{i j 1}$ & $L_{1}$ & $L_{2}$ & $L_{3}$ & $\cdots$ & $L_{48}$ & $L_{49}$ & $L_{50}$ \\
\hline$T_{1}$ & 1 & 1 & 0 & $\cdots$ & 0 & 0 & 0 \\
$T_{2}$ & 1 & 1 & 0 & $\cdots$ & 0 & 0 & 0 \\
$T_{3}$ & 1 & 1 & 0 & $\cdots$ & 0 & 0 & 0 \\
$\vdots$ & $\vdots$ & $\vdots$ & $\vdots$ & $\ddots$ & $\vdots$ & $\vdots$ & $\vdots$ \\
$T_{48}$ & 0 & 0 & 0 & $\cdots$ & 0 & 0 & 1 \\
$T_{49}$ & 0 & 0 & 0 & $\cdots$ & 0 & 0 & 1 \\
$T_{50}$ & 0 & 0 & 0 & $\cdots$ & 0 & 0 & 1 \\
\hline
\end{tabular}

TABLE 7: Profit and loss matrix $F_{2}=\left[a_{i j 2}\right]_{50 \times 50}$ for landlords' housing rent.

\begin{tabular}{cccccccc}
\hline$a_{i j 2}$ & $L_{1}$ & $L_{2}$ & $L_{3}$ & $\cdots$ & $L_{48}$ & $L_{49}$ & $L_{50}$ \\
\hline$T_{1}$ & -0.0349 & 0.0000 & 0.0000 & $\cdots$ & -0.1552 & 0.0000 & -0.1923 \\
$T_{2}$ & -0.0581 & -0.0250 & 0.0000 & $\cdots$ & -0.1724 & 0.0000 & -0.2077 \\
$T_{3}$ & 0.0000 & 0.0000 & 0.0000 & $\cdots$ & 0.0000 & 0.0000 & 0.0000 \\
$\vdots$ & $\vdots$ & $\vdots$ & $\vdots$ & $\ddots$ & $\vdots$ & $\vdots$ & $\vdots$ \\
$T_{48}$ & -0.2442 & -0.2250 & -0.1563 & $\cdots$ & -0.3103 & -0.1563 & -0.3308 \\
$T_{49}$ & -0.0930 & -0.0625 & 0.0000 & $\cdots$ & -0.1983 & 0.0000 & -0.2308 \\
$T_{50}$ & 0.0000 & 0.0000 & 0.0000 & $\cdots$ & 0.0000 & 0.0000 & 0.0000 \\
\hline
\end{tabular}

TABLe 8: Profit and loss matrix $D_{1}=\left[d_{i j 1}\right]_{50 \times 50}$ for tenants' housing location.

\begin{tabular}{cccccccc}
\hline$d_{i j 1}$ & $L_{1}$ & $L_{2}$ & $L_{3}$ & $\cdots$ & $L_{48}$ & $L_{49}$ & $L_{50}$ \\
\hline$T_{1}$ & 1 & 1 & 0 & $\cdots$ & 0 & 0 & 0 \\
$T_{2}$ & 1 & 1 & 0 & $\cdots$ & 0 & 0 & 0 \\
$T_{3}$ & 1 & 1 & 0 & $\cdots$ & 0 & 0 & 0 \\
$\vdots$ & $\vdots$ & $\vdots$ & $\vdots$ & $\ddots$ & $\vdots$ & $\vdots$ & $\vdots$ \\
$T_{48}$ & 0 & 0 & 0 & $\cdots$ & 0 & 0 & 1 \\
$T_{49}$ & 0 & 0 & 0 & $\cdots$ & 0 & 0 & 1 \\
$T_{50}$ & 0 & 0 & 0 & $\cdots$ & 0 & 0 & 1 \\
\hline
\end{tabular}

TABle 9: Profit and loss matrix $D_{2}=\left[d_{i j 2}\right]_{50 \times 50}$ for tenants' transportation convenience.

\begin{tabular}{cccccccc}
\hline$d_{i j 2}$ & $L_{1}$ & $L_{2}$ & $L_{3}$ & $\cdots$ & $L_{48}$ & $L_{49}$ & $L_{50}$ \\
\hline$T_{1}$ & -1 & -1 & -1 & $\cdots$ & -1 & -3 & -3 \\
$T_{2}$ & 0 & 0 & 0 & $\cdots$ & 0 & -2 & -2 \\
$T_{3}$ & 0 & 0 & 0 & $\cdots$ & 0 & -2 & -2 \\
$\vdots$ & $\vdots$ & $\vdots$ & $\vdots$ & $\ddots$ & $\vdots$ & $\vdots$ & \\
$T_{48}$ & 1 & 1 & 1 & $\cdots$ & 1 & -1 & -1 \\
$T_{49}$ & 1 & 1 & 1 & $\cdots$ & 1 & -1 & -1 \\
$T_{50}$ & 1 & 1 & 1 & $\cdots$ & 1 & -1 & -1 \\
\hline
\end{tabular}


TABle 10: Normative profit and loss matrix $F_{1}^{\prime}=\left[a_{i j 1}{ }^{\prime}\right]_{50 \times 50}$ for landlords' housing location.

\begin{tabular}{cccccccc}
\hline$a_{i j 1}^{\prime}$ & $L_{1}$ & $L_{2}$ & $L_{3}$ & $\cdots$ & $L_{48}$ & $L_{49}$ & $L_{50}$ \\
\hline$T_{1}$ & 1 & 1 & 0 & $\cdots$ & 0 & 0 & 0 \\
$T_{2}$ & 1 & 1 & 0 & $\cdots$ & 0 & 0 & 0 \\
$T_{3}$ & 1 & 1 & 0 & $\cdots$ & 0 & 0 & 0 \\
$\vdots$ & $\vdots$ & $\vdots$ & $\vdots$ & $\ddots$ & $\vdots$ & $\vdots$ & $\vdots$ \\
$T_{48}$ & 0 & 0 & 0 & $\cdots$ & 0 & 0 & 1 \\
$T_{49}$ & 0 & 0 & 0 & $\cdots$ & 0 & 0 & 1 \\
$T_{50}$ & 0 & 0 & 0 & $\cdots$ & 0 & 0 & 1 \\
\hline
\end{tabular}

TABLE 11: Normative profit and loss matrix $F_{2}^{\prime}=\left[a_{i j 2}^{\prime}\right]_{50 \times 50}$ for landlords' housing rent.

\begin{tabular}{cccccccc}
\hline$a_{i j 2}^{\prime}$ & $L_{1}$ & $L_{2}$ & $L_{3}$ & $\cdots$ & $L_{48}$ & $L_{49}$ & $L_{50}$ \\
\hline$T_{1}$ & -0.0349 & 0.0000 & 0.0000 & $\cdots$ & -0.1552 & 0.0000 & -0.1923 \\
$T_{2}$ & -0.0581 & -0.0250 & 0.0000 & $\cdots$ & -0.1724 & 0.0000 & -0.2077 \\
$T_{3}$ & 0.0000 & 0.0000 & 0.0000 & $\cdots$ & 0.0000 & 0.0000 & 0.0000 \\
$\vdots$ & $\vdots$ & $\vdots$ & $\vdots$ & $\ddots$ & $\vdots$ & $\vdots$ & $\vdots$ \\
$T_{48}$ & -0.2442 & -0.2250 & -0.1563 & $\cdots$ & -0.3103 & -0.1563 & -0.3308 \\
$T_{49}$ & -0.0930 & -0.0625 & 0.0000 & $\cdots$ & -0.1983 & 0.0000 & -0.2308 \\
$T_{50}$ & 0.0000 & 0.0000 & 0.0000 & $\cdots$ & 0.0000 & 0.0000 & 0.0000 \\
\hline
\end{tabular}

TABLe 12: Normative profit and loss matrix $D_{1}^{\prime}=\left[d_{i j 1}{ }^{\prime}\right]_{50 \times 50}$ for tenants' housing location.

\begin{tabular}{cccccccc}
\hline$d_{i j 1}^{\prime}$ & $L_{1}$ & $L_{2}$ & $L_{3}$ & $\cdots$ & $L_{48}$ & $L_{49}$ & $L_{50}$ \\
\hline$T_{1}$ & 1 & 1 & 0 & $\cdots$ & 0 & 0 & 0 \\
$T_{2}$ & 1 & 1 & 0 & $\cdots$ & 0 & 0 & 0 \\
$T_{3}$ & 1 & 1 & 0 & $\cdots$ & 0 & 0 & 0 \\
$\vdots$ & $\vdots$ & $\vdots$ & $\vdots$ & $\ddots$ & $\vdots$ & $\vdots$ & $\vdots$ \\
$T_{48}$ & 0 & 0 & 0 & $\cdots$ & 0 & 0 & 1 \\
$T_{49}$ & 0 & 0 & 0 & $\cdots$ & 0 & 0 & 1 \\
$T_{50}$ & 0 & 0 & 0 & $\cdots$ & 0 & 0 & 1 \\
\hline
\end{tabular}

TABLE 13: Normative profit and loss matrix $D_{2}^{\prime}=\left[d_{i j 2}^{\prime}\right]_{50 \times 50}$ for tenants' transportation convenience.

\begin{tabular}{cccccccc}
\hline$d_{i j 2}^{\prime}$ & $L_{1}$ & $L_{2}$ & $L_{3}$ & $\cdots$ & $L_{48}$ & $L_{49}$ & $L_{50}$ \\
\hline$T_{1}$ & -0.25 & -0.25 & -0.25 & $\cdots$ & -0.25 & -0.75 & -0.75 \\
$T_{2}$ & 0 & 0 & 0 & $\cdots$ & 0 & -0.5 & -0.5 \\
$T_{3}$ & 0 & 0 & 0 & $\cdots$ & 0 & -0.5 & -0.5 \\
$\vdots$ & $\vdots$ & $\vdots$ & $\vdots$ & $\ddots$ & $\vdots$ & $\vdots$ & $\vdots$ \\
$T_{48}$ & 0.25 & 0.25 & 0.25 & $\cdots$ & 0.25 & -0.25 & -0.25 \\
$T_{49}$ & 0.25 & 0.25 & 0.25 & $\cdots$ & 0.25 & -0.25 & -0.25 \\
$T_{50}$ & 0.25 & 0.25 & 0.25 & $\cdots$ & 0.25 & -0.25 & -0.25 \\
\hline
\end{tabular}

remaining tenants' normative profit and loss matrices are given in Appendix.

Step 4: the perceived utility matrices $V_{l}^{s}=\left[v_{i j l}^{s}\right]_{50 \times 50}$ and $V_{l}^{b}=\left[v_{i j l}^{b}\right]_{50 \times 50}$ of the landlords and tenants, respectively, were calculated using equations (11) and (12). The landlords' perceived utility matrices $V_{l}^{s}=\left[v_{i j l}^{s}\right]_{50 \times 50}$ are shown in Tables 14 and 15, while the tenants' perceived utility matrices $V_{l}^{s}=\left[v_{i j l}^{s}\right]_{50 \times 50}$ for house
TABle 14: Perceived utility matrix $V_{1}^{s}=\left[v_{i j 1}^{s}\right]_{50 \times 50}$ for landlords' housing location.

\begin{tabular}{cccccccc}
\hline$v_{i j 1}^{s}$ & $L_{1}$ & $L_{2}$ & $L_{3}$ & $\cdots$ & $L_{48}$ & $L_{49}$ & $L_{50}$ \\
\hline$T_{1}$ & 0.2 & 0.2 & 0 & $\cdots$ & 0 & 0 & 0 \\
$T_{2}$ & 0.2 & 0.2 & 0 & $\cdots$ & 0 & 0 & 0 \\
$T_{3}$ & 0.2 & 0.2 & 0 & $\cdots$ & 0 & 0 & 0 \\
$\vdots$ & $\vdots$ & $\vdots$ & $\vdots$ & $\ddots$ & $\vdots$ & $\vdots$ & $\vdots$ \\
$T_{48}$ & 0 & 0 & 0 & $\cdots$ & 0 & 0 & 0.2 \\
$T_{49}$ & 0 & 0 & 0 & $\cdots$ & 0 & 0 & 0.2 \\
$T_{50}$ & 0 & 0 & 0 & $\cdots$ & 0 & 0 & 0.2 \\
\hline
\end{tabular}

TABLe 15: Perceived utility matrix $V_{2}^{s}=\left[v_{i j 2}^{s}\right]_{50 \times 50}$ for landlords' housing rent.

\begin{tabular}{cccccccc}
\hline$v_{i j 2}^{s}$ & $L_{1}$ & $L_{2}$ & $L_{3}$ & $\cdots$ & $L_{48}$ & $L_{49}$ & $L_{50}$ \\
\hline$T_{1}$ & -0.0078 & 0.0000 & 0.0000 & $\cdots$ & -0.0340 & 0.0000 & -0.0420 \\
$T_{2}$ & -0.0129 & -0.0056 & 0.0000 & $\cdots$ & -0.0377 & 0.0000 & -0.0453 \\
$T_{3}$ & 0.0000 & 0.0000 & 0.0000 & $\cdots$ & 0.0000 & 0.0000 & 0.0000 \\
$\vdots$ & $\vdots$ & $\vdots$ & $\vdots$ & $\ddots$ & $\vdots$ & $\vdots$ & $\vdots$ \\
$T_{48}$ & -0.0530 & -0.0490 & -0.0343 & $\cdots$ & -0.0669 & -0.0343 & -0.0712 \\
$T_{49}$ & -0.0205 & -0.0138 & 0.0000 & $\cdots$ & -0.0433 & 0.0000 & -0.0502 \\
$T_{50}$ & 0.0000 & 0.0000 & 0.0000 & $\cdots$ & 0.0000 & 0.0000 & 0.0000 \\
\hline
\end{tabular}

TABle 16: Perceived utility matrix $V_{1}^{b}=\left[v_{i j 1}^{b}\right]_{50 \times 50}$ for tenants' housing location.

\begin{tabular}{cccccccc}
\hline$v_{i j 1}^{b}$ & $L_{1}$ & $L_{2}$ & $L_{3}$ & $\cdots$ & $L_{48}$ & $L_{49}$ & $L_{50}$ \\
\hline$T_{1}$ & 0.2 & 0.2 & 0 & $\cdots$ & 0 & 0 & 0 \\
$T_{2}$ & 0.2 & 0.2 & 0 & $\cdots$ & 0 & 0 & 0 \\
$T_{3}$ & 0.2 & 0.2 & 0 & $\cdots$ & 0 & 0 & 0 \\
$\vdots$ & $\vdots$ & $\vdots$ & $\vdots$ & $\ddots$ & $\vdots$ & $\vdots$ & $\vdots$ \\
$T_{48}$ & 0 & 0 & 0 & $\cdots$ & 0 & 0 & 0.2 \\
$T_{49}$ & 0 & 0 & 0 & $\cdots$ & 0 & 0 & 0.2 \\
$T_{50}$ & 0 & 0 & 0 & $\cdots$ & 0 & 0 & 0.2 \\
\hline
\end{tabular}

TABLe 17: Perceived utility matrix $V_{2}^{b}=\left[v_{i j 2}^{b}\right]_{50 \times 50}$ for tenants' transportation convenience.

\begin{tabular}{cccccccc}
\hline$v_{i j 2}^{b}$ & $L_{1}$ & $L_{2}$ & $L_{3}$ & $\cdots$ & $L_{48}$ & $L_{49}$ & $L_{50}$ \\
\hline$T_{1}$ & -0.0543 & -0.0543 & -0.0543 & $\cdots$ & -0.0543 & -0.1541 & -0.1541 \\
$T_{2}$ & 0.0000 & 0.0000 & 0.0000 & $\cdots$ & 0.0000 & -0.1056 & -0.1056 \\
$T_{3}$ & 0.0000 & 0.0000 & 0.0000 & $\cdots$ & 0.0000 & -0.1056 & -0.1056 \\
$\vdots$ & $\vdots$ & $\vdots$ & $\vdots$ & $\ddots$ & $\vdots$ & $\vdots$ & $\vdots$ \\
$T_{48}$ & 0.0543 & 0.0543 & 0.0543 & $\cdots$ & 0.0543 & -0.0543 & -0.0543 \\
$T_{49}$ & 0.0543 & 0.0543 & 0.0543 & $\cdots$ & 0.0543 & -0.0543 & -0.0543 \\
$T_{50}$ & 0.0543 & 0.0543 & 0.0543 & $\cdots$ & 0.0543 & -0.0543 & -0.0543 \\
\hline
\end{tabular}

location and transportation convenience are shown in Tables 16 and 17 . The remaining perceived utility matrices for the tenants are given in Appendix.

Step 5: the landlords' and tenants' comprehensive perceived utility matrices, $V^{\prime}=\left[v_{i j}^{s}\right]_{50 \times 50}$ and $V=\left[v_{i j}^{b}\right]_{50 \times 50}$, receptively, were calculated using equations (13) and (14), as shown in Tables 18 and 19. 
TABLE 18: Comprehensive perceived utility matrix $V^{\prime}=\left[v_{i j}^{s}\right]_{50 \times 50}$ of landlords.

\begin{tabular}{cccccccc}
\hline$v_{i j}^{s}$ & $L_{1}$ & $L_{2}$ & $L_{3}$ & $\cdots$ & $L_{48}$ & $L_{49}$ & $L_{50}$ \\
\hline$T_{1}$ & 0.0961 & 0.1000 & 0.0000 & $\cdots$ & -0.0170 & 0.0000 & -0.0210 \\
$T_{2}$ & 0.0936 & 0.0972 & 0.0000 & $\cdots$ & -0.0189 & 0.0000 & -0.0226 \\
$T_{3}$ & 0.1000 & 0.1000 & 0.0000 & $\cdots$ & 0.0000 & 0.0000 & 0.0000 \\
$\vdots$ & $\vdots$ & $\vdots$ & $\vdots$ & $\ddots$ & $\vdots$ & $\vdots$ & $\vdots$ \\
$T_{48}$ & -0.0265 & -0.0245 & -0.0171 & $\cdots$ & -0.0335 & -0.0171 & 0.0644 \\
$T_{49}$ & -0.0103 & -0.0069 & 0.0000 & $\cdots$ & -0.0216 & 0.0000 & 0.0749 \\
$T_{50}$ & 0.0000 & 0.0000 & 0.0000 & $\cdots$ & 0.0000 & 0.0000 & 0.1000 \\
\hline
\end{tabular}

TABLe 19: Comprehensive perceived utility matrix $V=\left[v_{i j}^{b}\right]_{50 \times 50}$ of tenants.

\begin{tabular}{cccccccc}
\hline$v_{i j}^{b}$ & $L_{1}$ & $L_{2}$ & $L_{3}$ & $\cdots$ & $L_{48}$ & $L_{49}$ & $L_{50}$ \\
\hline$T_{1}$ & 0.0514 & 0.0544 & -0.0074 & $\cdots$ & 0.0088 & 0.0045 & -0.0017 \\
$T_{2}$ & 0.0724 & 0.0750 & 0.0148 & $\cdots$ & 0.0294 & 0.0260 & 0.0180 \\
$T_{3}$ & 0.0616 & 0.0621 & 0.0012 & $\cdots$ & 0.0291 & 0.0147 & 0.0209 \\
$\vdots$ & $\vdots$ & $\vdots$ & $\vdots$ & $\ddots$ & $\vdots$ & $\vdots$ & $\vdots$ \\
$T_{48}$ & 0.0062 & 0.0094 & 0.0162 & $\cdots$ & 0.0197 & 0.0275 & 0.0658 \\
$T_{49}$ & 0.0024 & 0.0056 & 0.0073 & $\cdots$ & 0.0211 & 0.0199 & 0.0694 \\
$T_{50}$ & -0.0264 & -0.0250 & -0.0264 & $\cdots$ & -0.0003 & -0.0151 & 0.0515 \\
\hline
\end{tabular}

According to the landlords' and tenants' comprehensive perceived utility matrices, the multiobjective optimization model, equation (17), was constructed as follows:

$$
\begin{array}{ll}
\max & Z_{1}=\sum_{i=1}^{50} \sum_{j=1}^{50} v_{i j}^{b} x_{i j}, \quad i=1,2,3, \ldots, 50 ; j=1,2,3, \ldots, 50 \\
\max & Z_{2}=\sum_{i=1}^{50} \sum_{j=1}^{50} v_{i j}^{s} x_{i j}, i=1,2,3, \ldots, 50 ; j=1,2,3, \ldots, 50 \\
& \sum_{i=1}^{50} x_{i j} \leq 1, \quad j=1,2,3, \ldots, 50 \\
& \sum_{j=1}^{50} x_{i j}=1, \quad i=1,2,3, \ldots, 50 \\
& \sum_{j=1}^{50} x_{i j} r_{i j}=1, \quad i=1,2,3, \ldots, 50 \\
& x_{i j}=0 \text { or } 1, \quad i=1,2,3, \ldots, 50, j=1,2,3, \ldots, 50 .
\end{array}
$$

Transforming the above multiobjective optimization model to a single-objective optimization model (equation (18)) was done as follows:

$$
\begin{array}{ll}
\max & Z=0.5 Z_{1}+0.5 Z_{2} \\
& \sum_{i=1}^{50} x_{i j} \leq 1, \quad j=1,2,3, \ldots, 50 \\
& \sum_{j=1}^{50} x_{i j}=1, \quad i=1,2,3, \ldots, 50 \\
& \sum_{j=1}^{50} x_{i j} r_{i j}=1, \quad i=1,2,3, \ldots, 50 \\
& x_{i j}=0 \text { or } 1, \quad i=1,2,3, \ldots, 50, j=1,2,3, \ldots, 50 .
\end{array}
$$

Step 6: the optimization model in equation (18) was solved using a genetic algorithm. The derived matching results are shown in Table 20.

As shown in Table 20, all tenants and landlords formed matching pairs. This not only shows matching results that are satisfactory to both sides-with an overall satisfaction value of the matching results of $Z=4.2374$-but also shows an improvement in matching efficiency. That is, the method reduces matching costs and time for both SAD. Therefore, the SAD matching method for ORH proposed in this study can provide reference to the multiattribute two-sided matching decision method and a basis for cracking the $\mathrm{ORH}$ SAD matching problem, which is characterized by multiagents and multilevel supply. The rationality and effectiveness of this method, given the multiple attributes of housing and both SAD sides' perceived utility, have been proved in matching the SAD of ORH.

In this study, a genetic algorithm is used to solve the final matching result of the model. The population evolution curve of the genetic algorithm is shown in Figure 8. As shown in the figure, when the population evolves to 200 generations, the objective function value reaches the optimal value and overall stability. In addition, the total running time of the algorithm is 87.8202 seconds, which is very short. When the scale of the problem is large, it is very feasible to apply genetic algorithms to solve the problem of matching SAD of online rental housing.

\subsection{Discussion}

4.2.1. Impact of the Weight of SAD. During the transaction between the SAD sides, the weights may not be fair, which may cause the matching result to be inconsistent with the actual situation. To further verify the rationality and comprehensiveness of the algorithm, we verified the weight of the SAD double from 0 to 1 , respectively. As shown in Figure 9, the overall satisfaction of the SAD sides increased as the weight of the landlord increased, but the opposite is true for the tenants. This may be because landlords have fewer housing attributes to consider during the transaction matching process.

4.2.2. Impact of the Number of $S A D$. For online housing platforms, the number of SAD sides may be unequal, and it may be a situation where suppliers exceed demanders. Therefore, to further verify the effectiveness of the model and algorithm, we attempted to calculate a situation in which the suppliers exceed demanders and added 5 pieces of rental information for calculation. It was found that when $m \leq n$, the overall satisfaction of both SAD sides became larger, $Z=4.3832$, which was 0.1458 higher than the satisfaction value when $m=n$. This may be caused by some tenants matching with more suitable landlords, making the satisfaction value higher. The influence of the SAD quantities on the overall satisfaction value $Z$ is shown in Figure 10. In summary, this model is applicable in matching the supply and demand of ORH. 
TABLE 20: Matching results of the multiattribute SAD matching decision model of ORH.

\begin{tabular}{|c|c|}
\hline Number & Results \\
\hline 1 & $\left(T_{1}, L_{2}\right)$ \\
\hline 2 & $\left(T_{2}, L_{1}\right)$ \\
\hline 3 & $\left(T_{3}, L_{22}\right)$ \\
\hline 4 & $\left(T_{4}, L_{4}\right)$ \\
\hline 5 & $\left(T_{5}, L_{3}\right)$ \\
\hline 6 & $\left(T_{6}, L_{23}\right)$ \\
\hline 7 & $\left(T_{7}, L_{5}\right)$ \\
\hline 8 & $\left(T_{8}, L_{24}\right)$ \\
\hline 9 & $\left(T_{9}, L_{25}\right)$ \\
\hline 10 & $\left(T_{10}, L_{6}\right)$ \\
\hline 11 & $\left(T_{11}, L_{27}\right)$ \\
\hline 12 & $\left(T_{12}, L_{26}\right)$ \\
\hline 13 & $\left(T_{13}, L_{43}\right)$ \\
\hline 14 & $\left(T_{14}, L_{7}\right)$ \\
\hline 15 & $\left(T_{15}, L_{8}\right)$ \\
\hline 16 & $\left(T_{16}, L_{28}\right)$ \\
\hline 17 & $\left(T_{17}, L_{9}\right)$ \\
\hline 18 & $\left(T_{18}, L_{10}\right)$ \\
\hline 19 & $\left(T_{19}, L_{29}\right)$ \\
\hline 20 & $\left(T_{20}, L_{30}\right)$ \\
\hline 21 & $\left(T_{21}, L_{11}\right)$ \\
\hline 22 & $\left(T_{22}, L_{12}\right)$ \\
\hline 23 & $\left(T_{23}, L_{31}\right)$ \\
\hline 24 & $\left(T_{24}, L_{44}\right)$ \\
\hline 25 & $\left(T_{25}, L_{13}\right)$ \\
\hline 26 & $\left(T_{26}, L_{14}\right)$ \\
\hline 27 & $\left(T_{37}, L_{42}\right)$ \\
\hline 28 & $\left(T_{28}, L_{45}\right)$ \\
\hline 29 & $\left(T_{29}, L_{39}\right)$ \\
\hline 30 & $\left(T_{30}, L_{34}\right)$ \\
\hline 31 & $\left(T_{31}, L_{35}\right)$ \\
\hline 32 & $\left(T_{32}, L_{46}\right)$ \\
\hline 33 & $\left(T_{33}, L_{16}\right)$ \\
\hline 34 & $\left(T_{34}, L_{15}\right)$ \\
\hline 35 & $\left(T_{35}, L_{36}\right)$ \\
\hline 36 & $\left(T_{36}, L_{47}\right)$ \\
\hline 37 & $\left(T_{37}, L_{17}\right)$ \\
\hline 38 & $\left(T_{38}, L_{38}\right)$ \\
\hline 39 & $\left(T_{9}, L_{25}\right)$ \\
\hline 40 & $\left(T_{40}, L_{48}\right)$ \\
\hline 41 & $\left(T_{41}, L_{18}\right)$ \\
\hline 42 & $\left(T_{42}, L_{19}\right)$ \\
\hline 43 & $\left(T_{43}, L_{39}\right)$ \\
\hline 44 & $\left(T_{44}, L_{20}\right)$ \\
\hline 45 & $\left(T_{45}, L_{40}\right)$ \\
\hline 46 & $\left(T_{46}, L_{49}\right)$ \\
\hline 47 & $\left(T_{47}, L_{41}\right)$ \\
\hline 48 & $\left(T_{48}, L_{21}\right)$ \\
\hline 49 & $\left(T_{9}, L_{25}\right)$ \\
\hline 50 & $\left(T_{50}, L_{50}\right)$ \\
\hline
\end{tabular}

Overall, from the analysis of the results, the weights occupied by the SAD affected the overall satisfaction value, but had no effect on the final matching result. In addition, this model is applicable when the supply is equal to the demand or the supply is greater than the demand. This study improves the two-sided matching theory and extends it to the online leasing market to provide matching efficiency between the SAD sides [1].

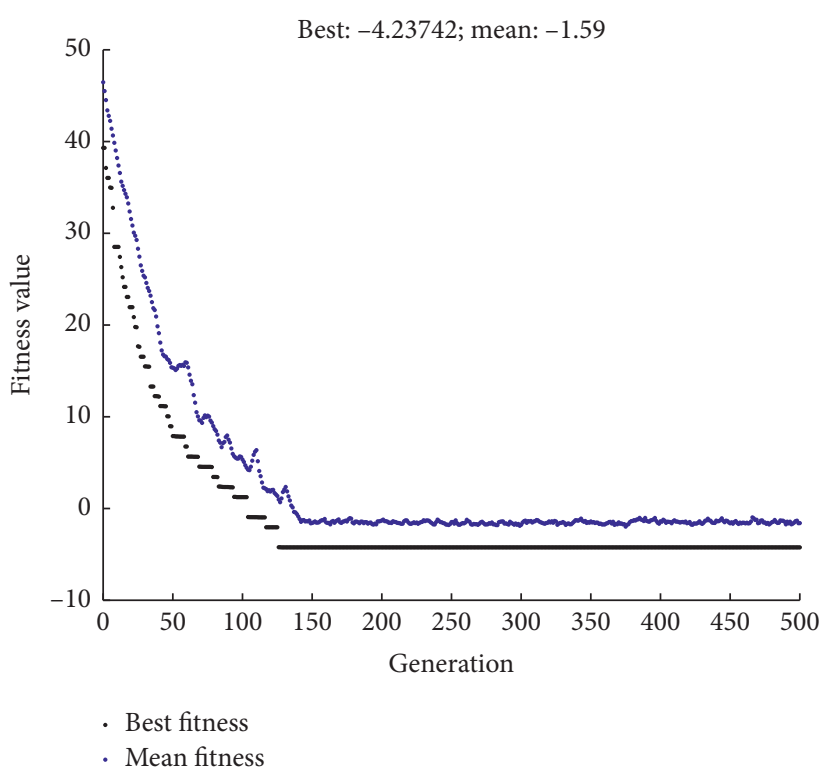

(a)

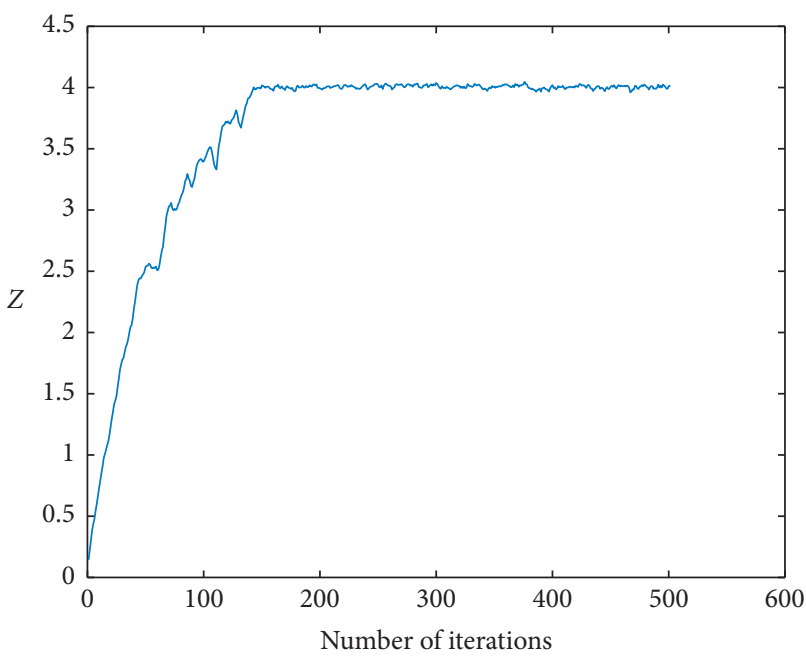

(b)

Figure 8: Genetic algorithm evolution curve. (a) Number of iterations. (b) Fitness function.

4.2.3. Comparison with Other Methods. The method proposed in this study may have some differences compared with other methods. With regard to model application, some literature studies have applied matching methods to fields such as hospital diagnosis, carpool matching, job and personnel matching, electronic market matching, electric power retailer and buyer matching, and technology market matching. However, application in the rental housing market is limited. From the perspective of model quantification methods, some scholars quantify the satisfaction values of the SAD based on fuzzy sets, triangular intuitionistic fuzzy numbers, and gray correlation analysis, but these methods do not consider the psychological behavior of participants. Therefore, we quantify the perceived utility value of the SAD sides based on the disappointment theory, starting from the perceptions of the SAD sides, which are 


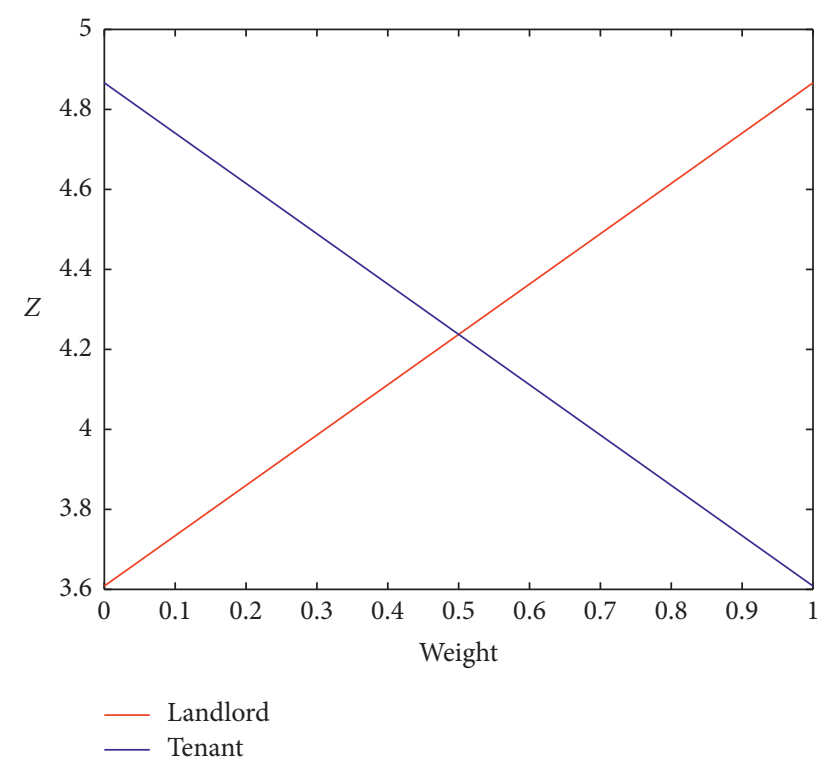

FIGURE 9: Influence of the weight of the SAD on the overall satisfaction value $Z$.

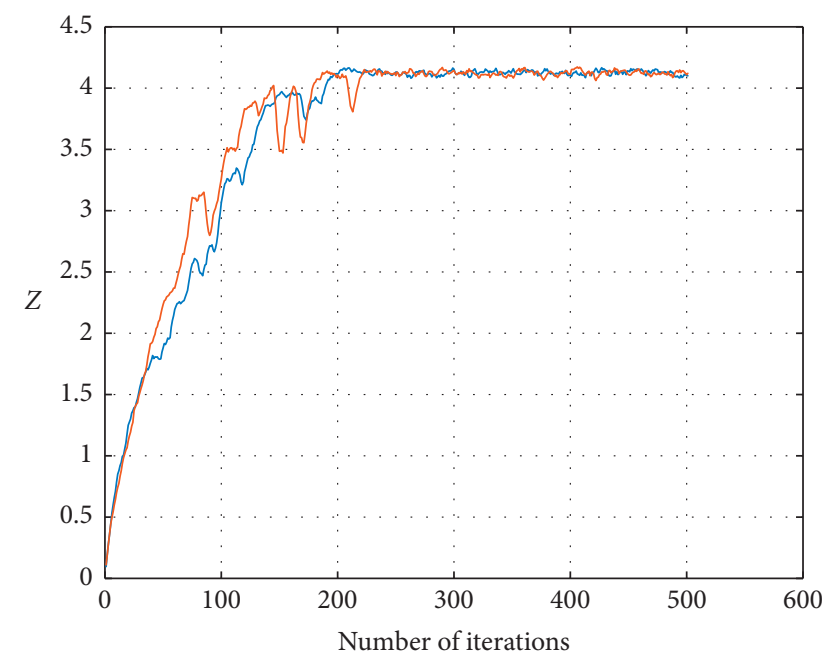

$$
-m=n
$$$$
-m \leq n
$$

FIGURE 10: Influence of the number of the SAD on the overall satisfaction value $Z$.

TABle 21: Profit and loss matrix $D_{3}=\left[d_{i j 3}\right]_{50 \times 50}$ for tenants' housing rent.

\begin{tabular}{cccccccc}
\hline$d_{i j 3}$ & $L_{1}$ & $L_{2}$ & $L_{3}$ & $\cdots$ & $L_{48}$ & $L_{49}$ & $L_{50}$ \\
\hline$T_{1}$ & -0.0375 & 0.0000 & 0.0000 & $\cdots$ & -0.2250 & 0.0000 & -0.3125 \\
$T_{2}$ & -0.0658 & -0.0263 & 0.0000 & $\cdots$ & -0.2632 & 0.0000 & -0.3553 \\
$T_{3}$ & 0.0000 & 0.0000 & 0.0000 & $\cdots$ & 0.0000 & 0.0000 & 0.0000 \\
$\vdots$ & $\vdots$ & $\vdots$ & $\vdots$ & $\ddots$ & $\vdots$ & $\vdots$ & $\vdots$ \\
$T_{48}$ & -0.4773 & -0.4091 & -0.2273 & $\cdots$ & -0.8182 & -0.2273 & -0.9773 \\
$T_{49}$ & -0.1143 & -0.0714 & 0.0000 & $\cdots$ & -0.3286 & 0.0000 & -0.4286 \\
$T_{50}$ & 0.0000 & 0.0000 & 0.0000 & $\cdots$ & 0.0000 & 0.0000 & 0.0000 \\
\hline
\end{tabular}

TABLe 22: Profit and loss matrix $D_{4}=\left[d_{i j 4}\right]_{50 \times 50}$ for tenants' living room.

\begin{tabular}{cccccccc}
\hline$d_{i j 4}$ & $L_{1}$ & $L_{2}$ & $L_{3}$ & $\cdots$ & $L_{48}$ & $L_{49}$ & $L_{50}$ \\
\hline$T_{1}$ & 0 & 0 & 0 & $\cdots$ & 2 & 2 & 2 \\
$T_{2}$ & 0 & 0 & 0 & $\cdots$ & 2 & 2 & 2 \\
$T_{3}$ & -1 & -1 & -1 & $\cdots$ & 1 & 1 & 1 \\
$\vdots$ & $\vdots$ & $\vdots$ & $\vdots$ & $\ddots$ & $\vdots$ & $\vdots$ & $\vdots$ \\
$T_{48}$ & 0 & 0 & 0 & $\cdots$ & 2 & 2 & 2 \\
$T_{49}$ & -1 & -1 & -1 & $\cdots$ & 1 & 1 & 1 \\
$T_{50}$ & -2 & -2 & -2 & $\cdots$ & 0 & 0 & 0 \\
\hline
\end{tabular}

TABle 23: Profit and loss matrix $D_{5}=\left[d_{i j 5}\right]_{50 \times 50}$ for tenants' housing matching.

\begin{tabular}{cccccccc}
\hline$d_{i j 5}$ & $L_{1}$ & $L_{2}$ & $L_{3}$ & $\cdots$ & $L_{48}$ & $L_{49}$ & $L_{50}$ \\
\hline$T_{1}$ & 0 & 0 & 0 & $\cdots$ & 0 & 0 & 0 \\
$T_{2}$ & 1 & 1 & 1 & $\cdots$ & 1 & 1 & 1 \\
$T_{3}$ & 0 & 0 & 0 & $\cdots$ & 0 & 0 & 0 \\
$\vdots$ & $\vdots$ & $\vdots$ & $\vdots$ & $\ddots$ & $\vdots$ & $\vdots$ & $\vdots$ \\
$T_{48}$ & 0 & 0 & 0 & $\cdots$ & 0 & 0 & 0 \\
$T_{49}$ & 0 & 0 & 0 & $\cdots$ & 0 & 0 & 0 \\
$T_{50}$ & 0 & 0 & 0 & $\cdots$ & 0 & 0 & 0 \\
\hline
\end{tabular}

TABle 24: Profit and loss matrix $D_{6}=\left[d_{i j 6}\right]_{50 \times 50}$ for tenants' housing decoration degree.

\begin{tabular}{cccccccc}
\hline$d_{i j 6}$ & $L_{1}$ & $L_{2}$ & $L_{3}$ & $\cdots$ & $L_{48}$ & $L_{49}$ & $L_{50}$ \\
\hline$T_{1}$ & 1 & 0 & 1 & $\cdots$ & 0 & 0 & 0 \\
$T_{2}$ & 1 & 0 & 1 & $\cdots$ & 1 & 1 & 1 \\
$T_{3}$ & 1 & 0 & 1 & $\cdots$ & 1 & 1 & 1 \\
$\vdots$ & $\vdots$ & $\vdots$ & $\vdots$ & $\ddots$ & $\vdots$ & $\vdots$ & $\vdots$ \\
$T_{48}$ & 1 & 0 & 1 & $\cdots$ & 1 & 1 & 1 \\
$T_{49}$ & 2 & 1 & 2 & $\cdots$ & 2 & 2 & 2 \\
$T_{50}$ & 1 & 0 & 1 & $\cdots$ & 1 & 1 & 1 \\
\hline
\end{tabular}

TABle 25: Profit and loss matrix $D_{7}=\left[d_{i j 7}\right]_{50 \times 50}$ for tenants' housing online ratings.

\begin{tabular}{cccccccc}
\hline$d_{i j 7}$ & $L_{1}$ & $L_{2}$ & $L_{3}$ & $\cdots$ & $L_{48}$ & $L_{49}$ & $L_{50}$ \\
\hline$T_{1}$ & 0 & 1 & 0 & $\cdots$ & -1 & -1 & 0 \\
$T_{2}$ & 1 & 2 & 1 & $\cdots$ & 0 & 0 & 1 \\
$T_{3}$ & 2 & 3 & 2 & $\cdots$ & 1 & 1 & 2 \\
$\vdots$ & $\vdots$ & $\vdots$ & $\vdots$ & $\ddots$ & $\vdots$ & $\vdots$ & $\vdots$ \\
$T_{48}$ & 2 & 3 & 2 & $\cdots$ & 1 & 1 & 2 \\
$T_{49}$ & 1 & 2 & 1 & $\cdots$ & 0 & 0 & 1 \\
$T_{50}$ & -1 & 0 & -1 & $\cdots$ & -2 & -2 & -1 \\
\hline
\end{tabular}

TABLE 26: Normative profit and loss matrix $D_{3}^{\prime}=\left[d_{i j 3}{ }^{\prime}\right]_{50 \times 50}$ for tenants' housing rent.

\begin{tabular}{cccccccc}
\hline$d_{i j 3}^{\prime}$ & $L_{1}$ & $L_{2}$ & $L_{3}$ & $\cdots$ & $L_{48}$ & $L_{49}$ & $L_{50}$ \\
\hline$T_{1}$ & -0.0375 & 0.0000 & 0.0000 & $\cdots$ & -0.2250 & 0.0000 & -0.3125 \\
$T_{2}$ & -0.0658 & -0.0263 & 0.0000 & $\cdots$ & -0.2632 & 0.0000 & -0.3553 \\
$T_{3}$ & 0.0000 & 0.0000 & 0.0000 & $\cdots$ & 0.0000 & 0.0000 & 0.0000 \\
$\vdots$ & $\vdots$ & $\vdots$ & $\vdots$ & $\ddots$ & $\vdots$ & $\vdots$ & $\vdots$ \\
$T_{48}$ & -0.4773 & -0.4091 & -0.2273 & $\cdots$ & -0.8182 & -0.2273 & -0.9773 \\
$T_{49}$ & -0.1143 & -0.0714 & 0.0000 & $\cdots$ & -0.3286 & 0.0000 & -0.4286 \\
$T_{50}$ & 0.0000 & 0.0000 & 0.0000 & $\cdots$ & 0.0000 & 0.0000 & 0.0000 \\
\hline
\end{tabular}


TABLe 27: Normative profit and loss matrix $D_{4}^{\prime}=\left[d_{i j 4}^{\prime}\right]_{50 \times 50}$ for tenants' living room.

\begin{tabular}{cccccccc}
\hline$d_{i j 4}^{\prime}$ & $L_{1}$ & $L_{2}$ & $L_{3}$ & $\cdots$ & $L_{48}$ & $L_{49}$ & $L_{50}$ \\
\hline$T_{1}$ & 0 & 0 & 0 & $\cdots$ & 1 & 1 & 1 \\
$T_{2}$ & 0 & 0 & 0 & $\cdots$ & 1 & 1 & 1 \\
$T_{3}$ & -0.5 & -0.5 & -0.5 & $\cdots$ & 0.5 & 0.5 & 0.5 \\
$\vdots$ & $\vdots$ & $\vdots$ & $\vdots$ & $\ddots$ & $\vdots$ & $\vdots$ & \\
$T_{48}$ & 0 & 0 & 0 & $\cdots$ & 1 & 1 & 1 \\
$T_{49}$ & -0.5 & -0.5 & -0.5 & $\cdots$ & 0.5 & 0.5 & 0.5 \\
$T_{50}$ & -1 & -1 & -1 & $\cdots$ & 0 & 0 & 0 \\
\hline
\end{tabular}

TABLE 28: Normative profit and loss matrix $D_{4}^{\prime}=\left[d_{i j 4}^{\prime}\right]_{50 \times 50}$ for tenants' housing matching.

\begin{tabular}{cccccccc}
\hline$d_{i j 5}^{\prime}$ & $L_{1}$ & $L_{2}$ & $L_{3}$ & $\cdots$ & $L_{48}$ & $L_{49}$ & $L_{50}$ \\
\hline$T_{1}$ & 0.0000 & 0.0000 & 0.0000 & $\cdots$ & 0.0000 & 0.0000 & 0.0000 \\
$T_{2}$ & 0.3333 & 0.3333 & 0.3333 & $\cdots$ & 0.3333 & 0.3333 & 0.3333 \\
$T_{3}$ & 0.0000 & 0.0000 & 0.0000 & $\cdots$ & 0.0000 & 0.0000 & 0.0000 \\
$\vdots$ & $\vdots$ & $\vdots$ & $\vdots$ & $\ddots$ & $\vdots$ & $\vdots$ & $\vdots$ \\
$T_{48}$ & 0.0000 & 0.0000 & 0.0000 & $\cdots$ & 0.0000 & 0.0000 & 0.0000 \\
$T_{49}$ & 0.0000 & 0.0000 & 0.0000 & $\cdots$ & 0.0000 & 0.0000 & 0.0000 \\
$T_{50}$ & 0.0000 & 0.0000 & 0.0000 & $\cdots$ & 0.0000 & 0.0000 & 0.0000 \\
\hline
\end{tabular}

TABLe 29: Normative profit and loss matrix $D_{6}^{\prime}=\left[d_{i j 6}{ }^{\prime}\right]_{50 \times 50}$ for tenants' housing decoration degree.

\begin{tabular}{cccccccc}
\hline$d_{i j 6}^{\prime}$ & $L_{1}$ & $L_{2}$ & $L_{3}$ & $\cdots$ & $L_{48}$ & $L_{49}$ & $L_{50}$ \\
\hline$T_{1}$ & 0.0000 & -0.3333 & 0.0000 & $\cdots$ & 0.0000 & 0.0000 & 0.0000 \\
$T_{2}$ & 0.3333 & 0.0000 & 0.3333 & $\cdots$ & 0.3333 & 0.3333 & 0.3333 \\
$T_{3}$ & 0.3333 & 0.0000 & 0.3333 & $\cdots$ & 0.3333 & 0.3333 & 0.3333 \\
$\vdots$ & $\vdots$ & $\vdots$ & $\vdots$ & $\ddots$ & $\vdots$ & $\vdots$ & $\vdots$ \\
$T_{48}$ & 0.3333 & 0.0000 & 0.3333 & $\cdots$ & 0.3333 & 0.3333 & 0.3333 \\
$T_{49}$ & 0.6667 & 0.3333 & 0.6667 & $\cdots$ & 0.6667 & 0.6667 & 0.6667 \\
$T_{50}$ & 0.3333 & 0.0000 & 0.3333 & $\cdots$ & 0.3333 & 0.3333 & 0.3333 \\
\hline
\end{tabular}

TABLe 30: Normative profit and loss matrix $D_{7}^{\prime}=\left[d_{i j 7}{ }^{\prime}\right]_{50 \times 50}$ for tenants' housing online ratings.

\begin{tabular}{cccccccc}
\hline$d_{i j 7}^{\prime}$ & $L_{1}$ & $L_{2}$ & $L_{3}$ & $\cdots$ & $L_{48}$ & $L_{49}$ & $L_{50}$ \\
\hline$T_{1}$ & 0.0000 & 0.3333 & 0.0000 & $\cdots$ & -0.3333 & -0.3333 & 0.0000 \\
$T_{2}$ & 0.3333 & 0.6667 & 0.3333 & $\cdots$ & 0.0000 & 0.0000 & 0.3333 \\
$T_{3}$ & 0.6667 & 1.0000 & 0.6667 & $\cdots$ & 0.3333 & 0.3333 & 0.6667 \\
$\vdots$ & $\vdots$ & $\vdots$ & $\vdots$ & $\ddots$ & $\vdots$ & $\vdots$ & $\vdots$ \\
$T_{48}$ & 0.6667 & 1.0000 & 0.6667 & $\cdots$ & 0.3333 & 0.3333 & 0.6667 \\
$T_{49}$ & 0.3333 & 0.6667 & 0.3333 & $\cdots$ & 0.0000 & 0.0000 & 0.3333 \\
$T_{50}$ & -0.3333 & 0.0000 & -0.3333 & $\cdots$ & -0.6667 & -0.6667 & -0.3333 \\
\hline
\end{tabular}

TABle 31: Perceived utility matrix $V_{3}^{b}=\left[v_{i j 3}^{b}\right]_{50 \times 50}$ for tenants' housing rent.

\begin{tabular}{cccccccc}
\hline$v_{i j 3}^{b}$ & $L_{1}$ & $L_{2}$ & $L_{3}$ & $\cdots$ & $L_{48}$ & $L_{49}$ & $L_{50}$ \\
\hline$T_{1}$ & -0.0083 & 0.0000 & 0.0000 & $\cdots$ & -0.0490 & 0.0000 & -0.0674 \\
$T_{2}$ & -0.0146 & -0.0059 & 0.0000 & $\cdots$ & -0.0570 & 0.0000 & -0.0762 \\
$T_{3}$ & 0.0000 & 0.0000 & 0.0000 & $\cdots$ & 0.0000 & 0.0000 & 0.0000 \\
$\vdots$ & $\vdots$ & $\vdots$ & $\vdots$ & $\ddots$ & $\vdots$ & $\vdots$ & $\vdots$ \\
$T_{48}$ & -0.1010 & -0.0872 & -0.0494 & $\cdots$ & -0.1669 & -0.0494 & -0.1959 \\
$T_{49}$ & -0.0252 & -0.0158 & 0.0000 & $\cdots$ & -0.0707 & 0.0000 & -0.0912 \\
$T_{50}$ & 0.0000 & 0.0000 & 0.0000 & $\cdots$ & 0.0000 & 0.0000 & 0.0000 \\
\hline
\end{tabular}

TABle 32: Perceived utility matrix $V_{4}^{b}=\left[v_{i j 4}^{b}\right]_{50 \times 50}$ for tenants' living room.

\begin{tabular}{cccccccc}
\hline$v_{i j 4}^{b}$ & $L_{1}$ & $L_{2}$ & $L_{3}$ & $\cdots$ & $L_{48}$ & $L_{49}$ & $L_{50}$ \\
\hline$T_{1}$ & 0.0000 & 0.0000 & 0.0000 & $\cdots$ & 0.2000 & 0.2000 & 0.2000 \\
$T_{2}$ & 0.0000 & 0.0000 & 0.0000 & $\cdots$ & 0.2000 & 0.2000 & 0.2000 \\
$T_{3}$ & -0.1056 & -0.1056 & -0.1056 & $\cdots$ & 0.1056 & 0.1056 & 0.1056 \\
$\vdots$ & $\vdots$ & $\vdots$ & $\vdots$ & $\ddots$ & $\vdots$ & $\vdots$ & $\vdots$ \\
$T_{48}$ & 0.0000 & 0.0000 & 0.0000 & $\cdots$ & 0.2000 & 0.2000 & 0.2000 \\
$T_{49}$ & -0.1056 & -0.1056 & -0.1056 & $\cdots$ & 0.1056 & 0.1056 & 0.1056 \\
$T_{50}$ & -0.2000 & -0.2000 & -0.2000 & $\cdots$ & 0.0000 & 0.0000 & 0.0000 \\
\hline
\end{tabular}

TABLE 33: Perceived utility matrix $V_{5}^{b}=\left[v_{i j 5}^{b}\right]_{50 \times 50}$ for tenants' housing matching.

\begin{tabular}{cccccccc}
\hline$v_{i j 5}^{b}$ & $L_{1}$ & $L_{2}$ & $L_{3}$ & $\cdots$ & $L_{48}$ & $L_{49}$ & $L_{50}$ \\
\hline$T_{1}$ & 0.0000 & 0.0000 & 0.0000 & $\cdots$ & 0.0000 & 0.0000 & 0.0000 \\
$T_{2}$ & 0.0717 & 0.0717 & 0.0717 & $\cdots$ & 0.0717 & 0.0717 & 0.0717 \\
$T_{3}$ & 0.0000 & 0.0000 & 0.0000 & $\cdots$ & 0.0000 & 0.0000 & 0.0000 \\
$\vdots$ & $\vdots$ & $\vdots$ & $\vdots$ & $\ddots$ & $\vdots$ & $\vdots$ & $\vdots$ \\
$T_{48}$ & 0.0000 & 0.0000 & 0.0000 & $\cdots$ & 0.0000 & 0.0000 & 0.0000 \\
$T_{49}$ & 0.0000 & 0.0000 & 0.0000 & $\cdots$ & 0.0000 & 0.0000 & 0.0000 \\
$T_{50}$ & 0.0000 & 0.0000 & 0.0000 & $\cdots$ & 0.0000 & 0.0000 & 0.0000 \\
\hline
\end{tabular}

TABLE 34: Perceived utility matrix $V_{6}^{b}=\left[v_{i j 6}^{b}\right]_{50 \times 50}$ for tenants' housing decoration degree.

\begin{tabular}{cccccccc}
\hline$v_{i j 6}^{b}$ & $L_{1}$ & $L_{2}$ & $L_{3}$ & $\cdots$ & $L_{48}$ & $L_{49}$ & $L_{50}$ \\
\hline$T_{1}$ & 0.0000 & -0.0717 & 0.0000 & $\cdots$ & 0.0000 & 0.0000 & 0.0000 \\
$T_{2}$ & 0.0717 & 0.0000 & 0.0717 & $\cdots$ & 0.0717 & 0.0717 & 0.0717 \\
$T_{3}$ & 0.0717 & 0.0000 & 0.0717 & $\cdots$ & 0.0717 & 0.0717 & 0.0717 \\
$\vdots$ & $\vdots$ & $\vdots$ & $\vdots$ & $\ddots$ & $\vdots$ & $\vdots$ & $\vdots$ \\
$T_{48}$ & 0.0717 & 0.0000 & 0.0717 & $\cdots$ & 0.0717 & 0.0717 & 0.0717 \\
$T_{49}$ & 0.1382 & 0.0717 & 0.1382 & $\cdots$ & 0.1382 & 0.1382 & 0.1382 \\
$T_{50}$ & 0.0717 & 0.0000 & 0.0717 & $\cdots$ & 0.0717 & 0.0717 & 0.0717 \\
\hline
\end{tabular}

TABle 35: Perceived utility matrix $V_{7}^{b}=\left[v_{i j 7}^{b}\right]_{50 \times 50}$ for tenants' housing online ratings.

\begin{tabular}{cccccccc}
\hline$v_{i j 7}^{b}$ & $L_{1}$ & $L_{2}$ & $L_{3}$ & $\cdots$ & $L_{48}$ & $L_{49}$ & $L_{50}$ \\
\hline$T_{1}$ & 0.0000 & 0.0717 & 0.0000 & $\cdots$ & -0.0717 & -0.0717 & 0.0000 \\
$T_{2}$ & 0.0717 & 0.1382 & 0.0717 & $\cdots$ & 0.0000 & 0.0000 & 0.0717 \\
$T_{3}$ & 0.1382 & 0.2000 & 0.1382 & $\cdots$ & 0.0717 & 0.0717 & 0.1382 \\
$\vdots$ & $\vdots$ & $\vdots$ & $\vdots$ & $\ddots$ & $\vdots$ & $\vdots$ & $\vdots$ \\
$T_{48}$ & 0.1382 & 0.2000 & 0.1382 & $\cdots$ & 0.0717 & 0.0717 & 0.1382 \\
$T_{49}$ & 0.0717 & 0.1382 & 0.0717 & $\cdots$ & 0.0000 & 0.0000 & 0.0717 \\
$T_{50}$ & -0.0717 & 0.0000 & -0.0717 & $\cdots$ & -0.1382 & -0.1382 & -0.0717 \\
\hline
\end{tabular}

highly significant for improving the overall matching satisfaction.

The matching decision method for second-hand housing transactions [41] and the two-sided matching decision method for second-hand housing, which considers the online rental/sale matching attribute association [36], are two relatively close cases. Regarding the matching algorithm, Haaimin [41] designed an extended H-R algorithm that considers that the stability of the matching scheme and the computational workload is large when obtaining matching 
results. Wang et al. [36] used the min-max method and uses LINGO software to solve the matching scheme. Although this method is simple and easy to operate, it is not suitable for large-scale two-sided matching problems. For the satisfaction of both SAD, Haaimin [41] ignored the psychological characteristics of misfortunes to avoid losses and maximize advantages. However, the current multiattribute two-sided matching decision model can maximize the satisfaction of SAD. Meanwhile, not only does the genetic algorithm applied in this study solve the large-scale twosided matching problem but also has a short running time, which can quickly and effectively promote effective matching between SAD.

\section{Conclusions and Implication}

In this study, an ORH multiattribute SAD matching decision model based on the perceived utility is constructed. This model determines the multiattribute indicators and proportions of housing that both SAD sides are interested in. By considering the psychological expectations of both SAD in measuring the perceived utility values, this model maximizes the overall satisfaction of both SAD. Finally, using Shanghai's online rental and demand information, a genetic algorithm is used to numerically analyze and solve the model, which not only obtains optimal matching results but also proves that the genetic algorithm can solve a large two-sided matching problem. This model enriches the application of double-sided matching theory and provides a reference method for online rental SAD matching. At the same time, this model considers that the psychological perceptions of the SAD sides can maximize their overall satisfaction and promote the matching accuracy of the model.

In the context of "Internet +" and big data, the effective matching of online rental lists is of great implication for promoting the effective operation of the rental housing market. In a theoretical sense, this study enriches the research on rental housing, with particular application for rental platforms, providing a new perspective for the development of rental platforms. In addition, it can be applied to the rental housing markets of other cities. Objectively, the model improves the effective docking of SAD and improves the supply side's efficiency. Subjectively, the enthusiasm for SAD interaction is realized. Therefore, this study has a reference basis for promoting the effective matching of online SAD and the improvement of satisfaction of both SAD.

As with any study, the article at hand suffers from several limitations that are worth considering in further research. Firstly, the method proposed in this study improves the overall matching between the SAD, but it needs to be further compared with other decision-making methods. Such as in the future, we will further study to compare it with other methods that actually produce results. Second, because the economic and social backgrounds of each SAD subject are different, the characteristic variables of the SAD matching decision model in different cities may be different. In the future, we will adjust the multiattribute equations and quantitative standards according to the characteristics of different cities. In addition, the actual practice results should be used to verify the SAD matching decision model in different cities to promote the sustainable development of the rental housing market.

Furthermore, in the transaction process of the $\mathrm{ORH}$ platforms, the multiattribute expectations of both parties should be considered. Regardless of the tenants or landlords, each subject considers their own subject's interests based on multiple values, which will directly or indirectly reflect the expected value of the property. Moreover, the supply side of the rental housing market should increase the information symmetry of SAD subjects to ensure that the information is transparent and open and that the transaction process is standardized, guaranteeing easy access to information for both parties.

\section{Appendix}

The remaining profit and loss matrices for tenants are given in Tables $21-25$, respectively.

The remaining normative profit and loss matrices for tenants are given in Tables 26-30, respectively.

The remaining perceived utility matrices for tenants are given in Tables 31-35, respectively.

\section{Data Availability}

The data used to support the findings of this study are available from the corresponding author upon request.

\section{Conflicts of Interest}

The authors declare no conflicts of interest.

\section{Acknowledgments}

This research was supported by the National Key R\&D Program of China (grant no. 2018YFD1100202), the Ministry of Education Humanistic and Social Science Program of China (grant no. 19YJC630080), the General Project of Shaanxi Province Soft Science Research Program (grant no. 2019KRM197), the Philosophy and Social Science Research Program of Education Department of Shaanxi Province (grant no.12JK0070), and the Shaanxi Social Science Fund General Project (grant no. 2015R006).

\section{References}

[1] A. G. Sharam, "Disruption and the matching market for new multifamily housing in Melbourne, Australia," Journal of General Management, vol. 44, no. 3, pp. 160-169, 2019.

[2] A. F. A. Saleh, T. K. Hwa, and R. Majid, "Housing mismatch model in suburban areas," Procedia-Social and Behavioral Sciences, vol. 234, pp. 442-451, 2016.

[3] G. Boeing, J. Wegmann, and J. Jiao, "Rental housing spot markets: how online information exchanges can supplement transacted-rents data," Journal of Planning Education and Research, 2020.

[4] K. A. Kholodilin, "Quantifying a century of state intervention in rental housing in Germany," Urban Research \& Practice, vol. 10, no. 3, pp. 267-328, 2017. 
[5] O. O. Makinde, "Housing delivery system, need and demand," Environment, Development and Sustainability, vol. 16, no. 1, pp. 49-69, 2014.

[6] Z. Z. Jin Lang, "Problems and development countermeasures of China's housing leasing market," Macroeconomic Management, vol. 3, pp. 80-85, 2018.

[7] L. Li, L. Feng, X. Guo, H. Xie, and W. Shi, "Complex network analysis of transmission mechanism for sustainable incentive policies," Sustainability, vol. 12, no. 2, p. 745, 2020.

[8] C.-H. Chen, F.-J. Hwang, and H.-Y. Kung, "Travel time prediction system based on data clustering for waste collection vehicles," IEICE Transactions on Information and Systems, vol. E102.D, no. 7, pp. 1374-1383, 2019.

[9] A. Manduchi, A. Petreski, and A. Stephan, "Market for apartment swap and rental market," SSRN Electronic Journal, 2019.

[10] S. Zhou, H. Sun, T. Guan, and T. Li, "Equilibrium model of housing choice for heterogeneous households under public rental housing policy," Sustainability, vol. 10, no. 12, p. 4505, 2018.

[11] J. Liu, Y. Zhan, and X. Ma, Research on Demand of Replacing to Public Rental Housing Tenants in Chongqing, Springer, Berlin, Germany, 2017.

[12] X. Sun and K. P. Tsang, "What drives the owner-occupied and rental housing markets? Evidence from an estimated DSGE model," Journal of Money, Credit and Banking, vol. 49, no. 2-3, pp. 443-468, 2017.

[13] H. Fu, M. Wang, P. Li et al., "Tracing knowledge development trajectories of the Internet of things domain: a main path analysis," IEEE Transactions on Industrial Informatics, vol. 15, no. 12, pp. 6531-6540, 2019.

[14] E. Lopez and D. Paredes, "Towards housing policies that consider household's preferences: estimating the demand for housing attributes in Chile," International Journal of Strategic Property Management, vol. 24, no. 1, pp. 24-36, 2018.

[15] W. C. Wheaton, "Vacancy, search, and prices in a housing market matching model," Journal of Political Economy, vol. 98, no. 6, pp. 1270-1292, 1990.

[16] N. Meng and X. Xu, "Research on customer attention of online short-term rental platform," in Proceedings of the 2018 IEEE 3rd Advanced Information Technology, Electronic and Automation Control Conference (IAEAC), pp. 2455-2459, IEEE, Chongqing, China, October 2018.

[17] A. Tversky and D. Kahneman, "Loss aversion in riskless choice: a reference-dependent model," The Quarterly Journal of Economics, vol. 106, no. 4, pp. 1039-1061, 1991.

[18] D. Kahneman, "A perspective on judgment and choice: mapping bounded rationality," American Psychologist, vol. 58, no. 9, pp. 697-720, 2003.

[19] G. Gigerenzer, "Moral satisficing: rethinking moral behavior as bounded rationality," Topics in Cognitive Science, vol. 2, no. 3, pp. 528-554, 2010.

[20] J. F. de Medeiros, J. L. D. Ribeiro, and M. N. Cortimiglia, "Influence of perceived value on purchasing decisions of green products in Brazil," Journal of Cleaner Production, vol. 110, pp. $158-169,2016$.

[21] D. E. Bell, "Disappointment in decision making under uncertainty," Operations Research, vol. 33, no. 1, pp. 1-27, 1985.

[22] G. Loomes and R. Sugden, "Disappointment and dynamic consistency in choice under uncertainty," The Review of Economic Studies, vol. 53, no. 2, pp. 271-282, 1986.

[23] A. B. Makar, K. E. McMartin, M. Palese, and T. R. Tephly, "Formate assay in body fluids: application in methanol poisoning," Biochemical Medicine, vol. 13, no. 2, pp. 117-126, 1975.

[24] P. Delquié and A. Cillo, "Disappointment without prior expectation: a unifying perspective on decision under risk," Journal of Risk and Uncertainty, vol. 33, no. 3, pp. 197-215, 2006.

[25] K. C. Cheung, W. F. Chong, and S. C. P. Yam, "The optimal insurance under disappointment theories," Insurance: Mathematics and Economics, vol. 64, pp. 77-90, 2015.

[26] R. Zhao, M. Jin, P. Ren, and Q. Zhang, "Stable two-sided satisfied matching for ridesharing system based on preference orders," The Journal of Supercomputing, vol. 76, no. 2, pp. 1063-1081, 2020.

[27] J. Quan, X. Wang, and Y. Quan, “Effects of consumers' strategic behavior and psychological satisfaction on the retailer's pricing and inventory decisions," IEEE Access, vol. 7, pp. 178779-178787, 2019.

[28] Z. Zhang, X. Kou, I. Palomares, W. Yu, and J. Gao, "Stable two-sided matching decision making with incomplete fuzzy preference relations: a disappointment theory based approach," Applied Soft Computing, vol. 84, Article ID 105730, 2019.

[29] Z.-P. Fan, M.-Y. Li, and X. Zhang, "Satisfied two-sided matching: a method considering elation and disappointment of agents," Soft Computing, vol. 22, no. 21, pp. 7227-7241, 2018.

[30] A. E. Roth, "Common and conflicting interests in two-sided matching markets," European Economic Review, vol. 27, no. 1, pp. 75-96, 1985.

[31] D. Gale and L. S. Shapley, "College admissions and the stability of marriage," The American Mathematical Monthly, vol. 69, no. 1, pp. 9-15, 1962.

[32] F. Kojima and P. A. Pathak, "Incentives and stability in large two-sided matching markets," American Economic Review, vol. 99, no. 3, pp. 608-627, 2009.

[33] L. Tan, W. Su, S. Gao, J. Miao, Y. Cheng, and P. Cheng, "Pathflow matching: two-sided matching and multiobjective evolutionary algorithm for traffic scheduling in cloud date center network," Transactions on Emerging Telecommunications Technologies, 2019.

[34] C.-H. Chen, "A cell probe-based method for vehicle speed estimation," IEICE Transactions on Fundamentals of Electronics, Communications and Computer Sciences, vol. E103.A, no. 1, pp. 265-267, 2020.

[35] Y. Lin, Y.-M. Wang, and K.-S. Chin, “An enhanced approach for two-sided matching with 2-tuple linguistic multi-attribute preference," Soft Computing, vol. 23, no. 17, pp. 7977-7990, 2019.

[36] R. Wang, D. Li, and G. Yu, "Research on bilateral matching decision method considering attribute association in heterogeneous information environment," Journal of Intelligent \& Fuzzy Systems, vol. 38, no. 4, pp. 4779-4792, 2020.

[37] T. Gao, M. Huang, Q. Wang et al., "A systematic model of stable multilateral automated negotiation in e-market environment," Engineering Applications of Artificial Intelligence, vol. 74, pp. 134-145, 2018.

[38] Y. Kong, W. Huang, and B. Li, "The supply and demand mechanism of electric power retailers and cellular networks based on matching theory," Information, vol. 9, no. 8, p. 192, 2018.

[39] B. Xia, S. Shakkottai, and V. Subramanian, "Small-scale markets for a bilateral energy sharing economy," IEEE Transactions on Control of Network Systems, vol. 6, no. 3, pp. 1026-1037, 2019. 
[40] Y. Yang, S. Luo, J. Fan, X. Zhou, C. Fu, and G. Tang, "Study on specialist outpatient matching appointment and the balance matching model," Journal of Combinatorial Optimization, vol. 37, no. 1, pp. 20-39, 2019.

[41] H. M. Liang and Y. P. Jiang, "Decision-making method on second-hand house combination matching," Systems Engineering-Theory \& Practice, vol. 37, no. 2, pp. 358-367, 2015.

[42] J. Wang, B. Li, W. Li, and S. L. Yang, "Two-sided matching model based on cumulative prospect theory for decision making of two-way referral system," Journal of Interdisciplinary Mathematics, vol. 21, no. 5, pp. 1097-1102, 2018.

[43] X. Chen, J. Wang, H. Liang, J. Han, and F. Systems, "Hesitant multi-attribute two-sided matching: a perspective based on prospect theory," Journal of Intelligent \& Fuzzy Systems, vol. 36, no. 6, pp. 6343-6358, 2019.

[44] S. Grant and A. Kajii, "AUSI expected utility: an anticipated utility theory of relative disappointment aversion," Journal of Economic Behavior \& Organization, vol. 37, no. 3, pp. 277290, 1998.

[45] C. E. Laciana and E. U. Weber, "Correcting expected utility for comparisons between alternative outcomes: a unified parameterization of regret and disappointment," Journal of Risk and Uncertainty, vol. 36, no. 1, pp. 1-17, 2008.

[46] Y. Liu and K. W. Li, "A two-sided matching decision method for supply and demand of technological knowledge," Journal of Knowledge Management, vol. 21, no. 3, pp. 592-606, 2017.

[47] D. G. McVitie and L. B. Wilson, "Stable marriage assignment for unequal sets,” Bit, vol. 10, no. 3, pp. 295-309, 1970.

[48] C.-H. Chen, F. Song, F.-J. Hwang, L. Wu, and I. Applications, "A probability density function generator based on neural networks," Physica A: Statistical Mechanics and Its Applications, vol. 541, Article ID 123344, 2020.

[49] M. L. Doerfel, "What constitutes semantic network analysis? A comparison of research and methodologies," Connections, vol. 21, no. 2, pp. 16-26, 1998.

[50] L. Lalicic and C. Weismayer, "The role of authenticity in airbnb experiences," in Information and Communication Technologies in Tourism, pp. 781-794, Springer, Cham, Switzerland, 2017.

[51] C. Qiyue, "Structural entropy weight method for determining index weights," Systems Engineering-Theory \& Practice, vol. 30, pp. 1225-1228, 2017. 